\title{
Review Article \\ Solid-Phase Organic Synthesis and Catalysis: Some Recent Strategies Using Alumina, Silica, and Polyionic Resins
}

\author{
Basudeb Basu and Susmita Paul \\ Department of Chemistry, University of North Bengal, Darjeeling 734 013, India \\ Correspondence should be addressed to Basudeb Basu; basu_nbu@hotmail.com
}

Received 26 February 2013; Accepted 7 July 2013

Academic Editor: Raghunath V. Chaudhari

Copyright ( 2013 B. Basu and S. Paul. This is an open access article distributed under the Creative Commons Attribution License, which permits unrestricted use, distribution, and reproduction in any medium, provided the original work is properly cited.

\begin{abstract}
Solid-phase organic synthesis (SPOS) and catalysis have gained impetus after the seminal discovery of Merrifield's solid-phase peptide synthesis and also because of wide applicability in combinatorial and high throughput chemistry. A large number of organic, inorganic, or organic-inorganic hybrid materials have been employed as polymeric solid supports to promote or catalyze various organic reactions. This review article provides a concise account on our approaches involving the use of (i) alumina or silica, either having doped with metal salts or directly, and (ii) polyionic resins to either promote various organic reactions or to immobilize reagents/metal catalysts for subsequent use in hydrogenation and cross-coupling reactions. The reaction parameters, scopes, and limitations, particularly in the context of green chemistry, have been highlighted with pertinent approaches by other groups.
\end{abstract}

\section{Introduction}

The concept of solid-phase organic synthesis (SPOS) dates back mid-1940s, and the solid-phase peptide synthesis in 1960s developed by Merrifield has been a pioneering work [1]. Over the last two decades, there has been a surge generating tremendous interest in expanding this field of solid-phase synthesis [2-10]. There is a clear emphasis in synthetic chemistry towards developing environmentally friendly and sustainable routes to a myriad of materials. The emphasis is most apparent in the growth of green chemistry [1114]. According to Paul Anastas-one of the founders of the concepts of green chemistry, "Catalysis is a foundational stone of Green Chemistry" [11, 12]. One important aspect of clean technology is the usage of environmentally friendly surface catalysts, typically a solid catalyst that can be easily recovered when the reaction is complete [15]. Polymer supports play a critical role in combinatorial chemistry, and consequently, solid-phase organic synthesis continues to grow in importance [16-23]. One of the major advantages of this technique that has attracted attention of the chemists is the clean isolation of the products by simple filtration. As a result, this technique has become a valuable tool in combinatorial chemistry and high throughput chemistry, an integral part of drug discovery and research [24-26]. The solid-phase organic synthesis of small organic molecules depends largely on the adaptation of solution reactions to solid phase [27]. Alternative synthetic routes that avoid need of any toxic solvents and reduce the number of steps with high atom economy and energy efficiency are some of the key features of green chemistry. On the other hand, good dispersion of the active reagent sites, involving high selectivity, easier work-up, and improved efficiency are attractive features for solid-phase technology.

Both inorganic and organic polymers have been employed to mediate or promote organic reactions [28-30]. As regards use of inorganic oxides, silica and modified silica, alumina, zeolites, clays, and so forth have found wide applications in promoting various organic reactions in solution phase or in solvent-free conditions [31-38]. On the other hand, organic polymers such as polystyrene (PS) or that partially crosslinked with divinylbenzene (DVB) have remained the major choice besides uses of some other dendrimers [3950]. The choice of solid phase, polymers with suitable linkers, the nature of binding with the substrate/reagent (covalent or noncovalent), stability, and recyclability have remained some of the salient points for successful and efficient solid-phase synthetic protocol. 


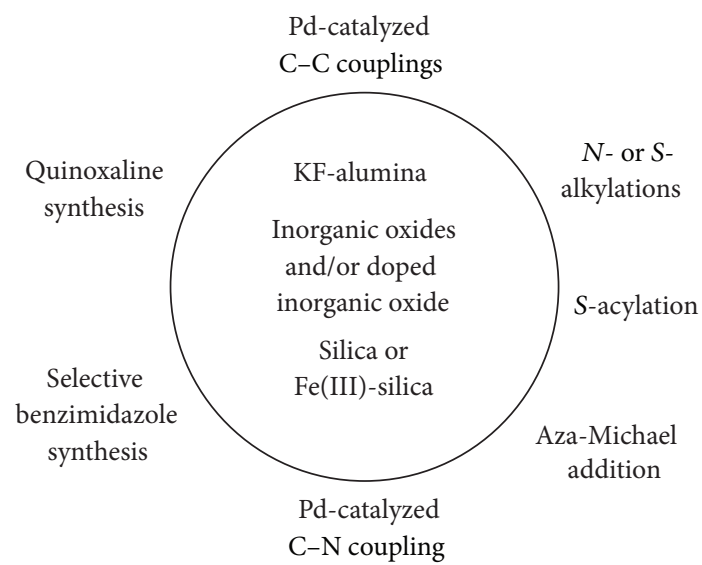

FIGURE 1

Towards developing new organic reactions and catalysis, our group has primarily employed two categories of polymers: (i) inorganic oxides either directly or having doped with some other inorganic salts, and (ii) polyionic resins to immobilize reagents/metal nanoparticles (NPs) as the solid-phase catalysts or heterogeneous nanocatalysts. This review article will primarily focus on our efforts vis-à-vis mentioning notable and relevant achievements from other research groups. The subject has been organized according to nature of the target molecules to synthesize, nature of reaction, and also the type of solid supports employed in various reactions.

Figure 1 illustrates examples of our efforts towards the synthesis of $\mathrm{C}-\mathrm{C}$ and $\mathrm{C}-\mathrm{X}$ (heteroatom) bond-forming reactions and synthesis of libraries of small heterocyclic molecules of biological importance having promoted or catalyzed on commercially available silica gel, alumina or doped with iron(III) salt or potassium fluoride, respectively.

\section{KF/Alumina Mediated/Catalyzed Organic Reactions}

Commercially available alumina $\left(\mathrm{Al}_{2} \mathrm{O}_{3}\right)$ is known to catalyze or promote a variety of organic transformations $[2,51]$. However, alumina doped with potassium fluoride (KF/alumina) has been extensively used as solid basic surface in vast range of organic transformation [52], since it was introduced by Ando et al. [53-56]. Alumina doped with KF can ionize $\mathrm{C}$-acids up to $\mathrm{pKa} \sim 35$ [57]. Although the actual basic site developed on the surface on alumina is dependent of temperature and partially debatable, the ${ }^{19} \mathrm{~F}$ magic angle NMR and IR spectroscopic measurements have shown that the fluoride anion species in $\mathrm{KF} /$ alumina is more electron rich than fluoride anion in pure solid. The conditions of loading of KF seem to be critical to its functioning and displaying varying properties.

2.1. Buchwald-Hartwig C-N Cross-Coupling Reaction. The first reaction was studied on the surface of KF/alumina is the Buchwald-Hartwig C-N cross-coupling reactions between aryl halides and an amine. Initial independent reports by
Buchwald and Hartwig clearly noticed that the success of such coupling is tricky to the use of the base, and sodium or potassium tert-butoxide was found to be best for such $\mathrm{C}-\mathrm{N}$ cross-coupling reactions [58-61]. Secondly, initial conditions were not successful for heteroaryl substrates, possibly because of formation of stable palladium complex that does not further participate in the catalytic cycle. Buchwald however circumvented this problem by using chelating ligands so as to avoid formation of substrate-based palladium complexes [62].

Palladium-catalyzed $\mathrm{C}-\mathrm{N}$ hetero cross-coupling reactions between bromopyridines and amines (both primary and secondary) can be efficiently performed on a KF/alumina (basic) surface (Scheme 1), thus negating the use of strong bases such as sodium tert-butoxide. The reaction conditions have been optimized with reference to catalytic systems, solvents, and the surface. A variety of phosphines both as mono- and bisphosphine ligands are found to be equally active [63].

To broaden the scope of this $\mathrm{C}-\mathrm{N}$ hetero cross-coupling, the reaction protocol has been extended to haloaromatics. The reactions are not only found to be applicable to bromoarenes but also offer high selectivity in cross-coupling of polyhaloaromatics. Indeed, there has been high selectivity between mono- or polyaminations (bis-, tris-, or tetra-) depending on the proportion of KF and alumina [64]. Higher proportion of $\mathrm{KF}$ and slight higher temperature can lead to polyamination, while lower amount of $\mathrm{KF}$ in $\mathrm{KF} /$ alumina generally affords only monoaminated product (Scheme 2).

Notable features of the use of KF doped with alumina (KF/alumina) are (i) the use of $\mathrm{NaOBu}^{t}$ can be avoided; (ii) conditions are not ligand-specific; (iii) solvent-free reactions generally give better yields; (iv) applicable to both bromoarenes and $N$-heteroaryl bromides; (v) varying proportions of KF per gram of alumina offer selectivity; and (vi) recycling of the solid surface is possible.

2.2. Double Michael Addition. The Michael addition reaction, an important $\mathrm{C}-\mathrm{C}$ bond-forming reaction, is known to produce adducts, which have found wide synthetic applications [65-68]. Several acidic and basic catalysts are used to affect this conjugate addition reaction. Side reactions, frequently encountered in the presence of a base catalyst, are secondary condensations, polymerizations, and double additions. However, the reactions in which two $\mathrm{C}-\mathrm{C}$ bonds are selectively formed by intermolecular and consecutive double Michael reactions in one-pot are very rare. It was observed that $\mathrm{KF} /$ alumina can promote consecutive Michael additions of the nucleophile derived from acetophenone to electron deficient alkenes. Thus, an efficient and highly selective one-pot procedure for the double Michael reactions was developed leading to the formation of pimelate ester derivatives [69]. This is the first example of selective double Michael additions of aromatic and aliphatic methyl ketones to electron-deficient alkenes mediated over KF/alumina (Scheme 3).

Both aliphatic and aromatic ketones underwent bisaddition with similar efficiencies and afforded the desired products. Mixture of acetone and ethyl acrylate yielded the 

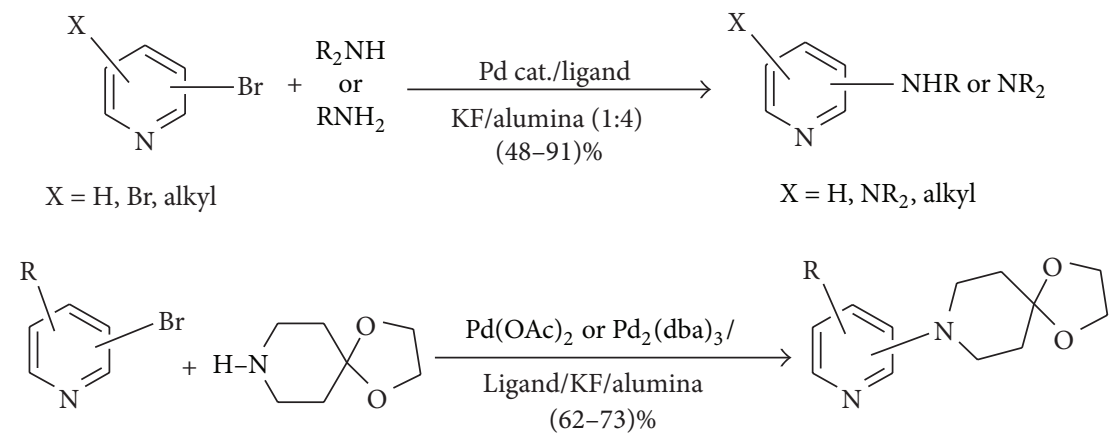

SCHEME 1

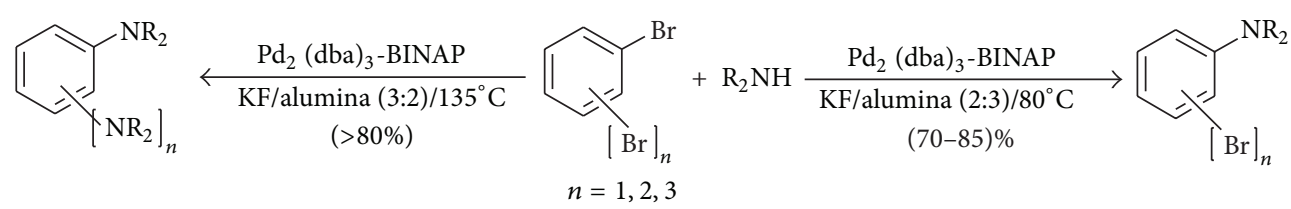

SCHEME 2<smiles>CCOC(=O)CCCC(CCC(=O)OCC)C(=O)c1ccccc1</smiles>

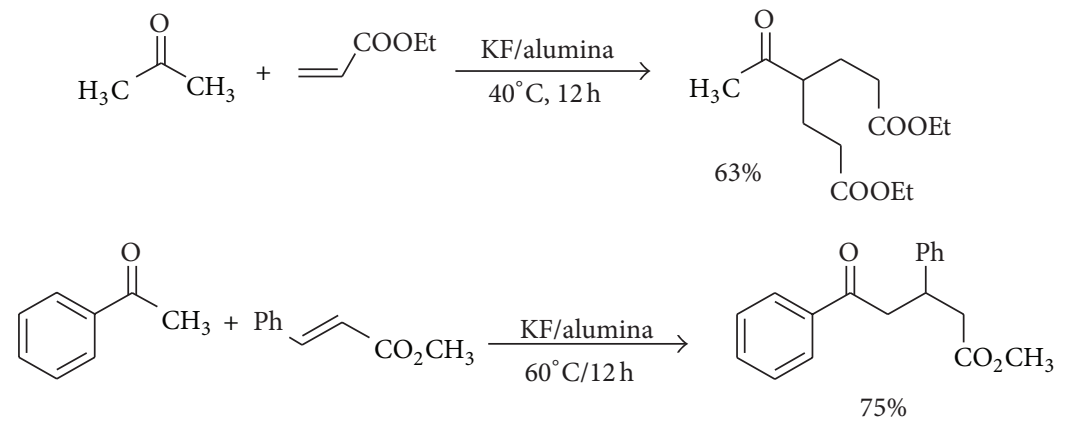

SCHEME 3

corresponding bis-adduct, diethyl 3-acetyl-heptanedioate, in $63 \%$ yield, keeping the other methyl group intact. While testing similar reactions using methyl crotonate or methyl cinnamate as the Michael acceptors, the reaction ended up selectively with the formation of monoadducts only even after prolonged reaction time and elevated temperatures. The possible reason of reluctance to undergo double additions may be attributed to the steric inhibition at the $\beta$-carbon of the conjugated olefins. This was further corroborated with the result that the double Michael adduct was indeed formed in $72 \%$ yield with methyl methacrylate.

2.3. Suzuki Coupling Reaction. Biaryls and higher homologues are an important class of conjugated polyaromatic compounds, originating from benzene as unique building blocks. Polyaryls have found wide range of applications as liquid crystals, laser-dyes, and conducting polymers. In addition, biaryls and higher homologues are often present as subunits in numerous biologically active natural products, pharmaceuticals and agrochemicals [70-80]. An efficient palladium-catalyzed cross-coupling of polyhaloaromatics with arylboronic acids on KF/alumina was developed under microwave-assisted condition (Scheme 4) [81]. The results have expanded the scope of the Suzuki reaction on a solventfree inorganic surface leading to the synthesis of a large variety of polyaromatics. The reaction is fast, operationally simple, and allows rapid access to a variety of polyaromatic hydrocarbons.

2.4. N-Arylation of Amines. An experimentally simple microwave-assisted solvent-free $N$-arylation of primary amines with sodium tetraphenylborate or arylboronic acids, 


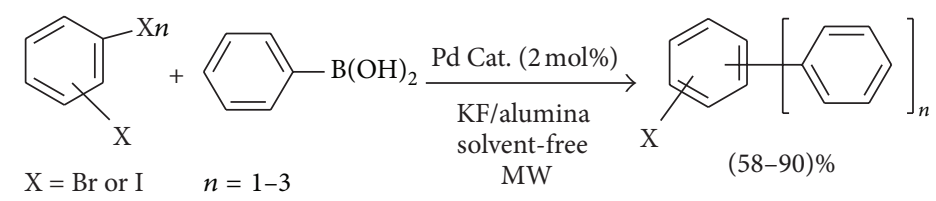

SCHEME 4

promoted by inexpensive cupric acetate, on the surface of KF/alumina has been developed (Scheme 5) [82]. The reaction is selective for mono- $N$-arylation, and a variety of functional groups are tolerated in the process establishing the versatility of KF/alumina.

Primary amines were monoarylated successfully using either sodium tetraphenylborate or arylboronic acids. Aromatic amines bearing either electron-donating or electronwithdrawing groups gave the corresponding unsymmetrical diarylamines in good to excellent yields. Aliphatic primary amines and benzylamine also produced $N$-arylated products in $70-75 \%$ yields. Halo-substitutions, either on the aryl amine or the arylboronic acid, remained unaffected under the reaction conditions.

2.5. Synthesis of Quinoxalines. Functionalized quinoxalines represent a privileged class of $\mathrm{N}$-containing heterocycles and exhibit a wide range of biological activities including antiviral, antibacterial, anthelmintic, anti-inflammatory, kinase inhibitory, and anticancer activities [83-89]. A facile and expeditious solid-phase synthesis of libraries of quinoxalines promoted on KF/alumina surface via tandem oxidationcondensation or condensation reactions has been developed (Scheme 6) [90]. The reaction protocol is operationally simple and mild. Moreover, solvent-free reaction condition makes the reaction procedure eco-friendly and economically viable. The methodology has been established as a direct and expeditious process of preparation of functionalized quinoxalines from different substrates like $\alpha$-hydroxy ketones, $\alpha$ bromoketones, or $\alpha$-dicarbonyl compounds, using a heterogeneous basic surface of KF/alumina.

\section{Reactions Promoted by Silica Gel}

Silica gel is nontoxic, nonflammable, nonreactive, and stable with ordinary usage. In chemistry, silica gel is used in chromatography as a stationary phase [91]. Owing to its highly developed surface $\left(5-800 \mathrm{~m}^{2} \mathrm{~g}^{-1}\right)$ and high porosity, it is used as sorbent for dehydration of gases and fluid, as a catalyst support for various reactions. Chemical reactions catalyzed or promoted by silica gel usually proceed under mild conditions and with high chemo-, regio-, and stereoselectivity and are operationally simple. In the quest of developing solid surface mediated organic reactions, a few reactions are described using silica gel as a potential surface.

3.1. Hetero-Michael Conjugate Additions. $\beta$-Amino ester and its derivatives are attractive targets for chemical synthesis of products with a wide range of biological activities and

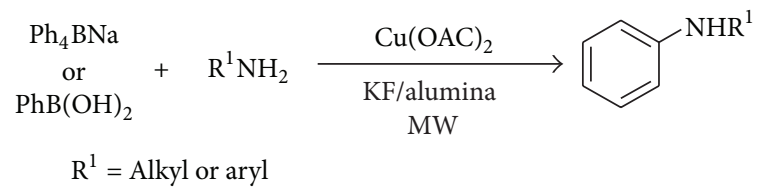

SCHEMe 5

pharmacological properties [92-94]. $\beta$-Amino esters are useful intermediates in certain attractive syntheses of $\beta$ lactam antibiotics [95-97]. Optically active $\beta$-amino esters and derivatives often find applications as chiral auxiliaries in asymmetric synthesis [98]. A solvent-free protocol for the synthesis of $\beta$-amino esters and nitriles has been developed via conjugate addition of amines to electron-deficient alkenes promoted on silica gel. The silica surface may be recovered and recycled. Both aliphatic and aromatic primary or secondary amines worked efficiently to yield the desired adducts in good to excellent yields (Scheme 7) [99]. The method has been found to be mostly successful when the silica gel of the type used for thin layer chromatography is used. Bulky hindered secondary amines such as diisopropylamine and dicyclohexylamine that were previously reported to be unproductive could efficiently undergo aza-Michael additions to produce corresponding $\beta$-amino esters [100]. It was interesting to see that $o$-amino thiol bearing both heteroatoms ( $\mathrm{N}$ and $\mathrm{S}$ ) could afford the bis-adduct, which indicates that thiols are also reactive under similar conditions (Scheme 7).

In general, the reactions proceed smoothly under solventfree conditions except in the eventual purification by column chromatography. Few reactions have been scaled up to $10 \mathrm{mmol}$ of the amines, and the desired products are isolated without any significant change of yield. The applicability of this "green" methodology to a diverse variety of amines including aromatic and sterically hindered amines remains to be the attractive feature and can be utilized by synthetic and industrial chemists.

3.2. Selective N-Alkylation of Amines. Further application of silica gel has been observed in selective $\mathrm{N}$-alkylation of amines. Traditionally, amines are alkylated in solution phase using inorganic acids as the catalysts and alkyl halides or dimethyl sulphate as the alkylating agents [101-111], besides methanol [112] and dimethyl carbonate [113]. However, yields or product-selectivity (mono- or bis-alkylations) are, with few exceptions, low and depend on the nature of the catalysts and reaction conditions. Though direct nucleophilic attack of amines to alkyl halides using a strong base is the most straightforward procedure; over alkylation, use of strong 


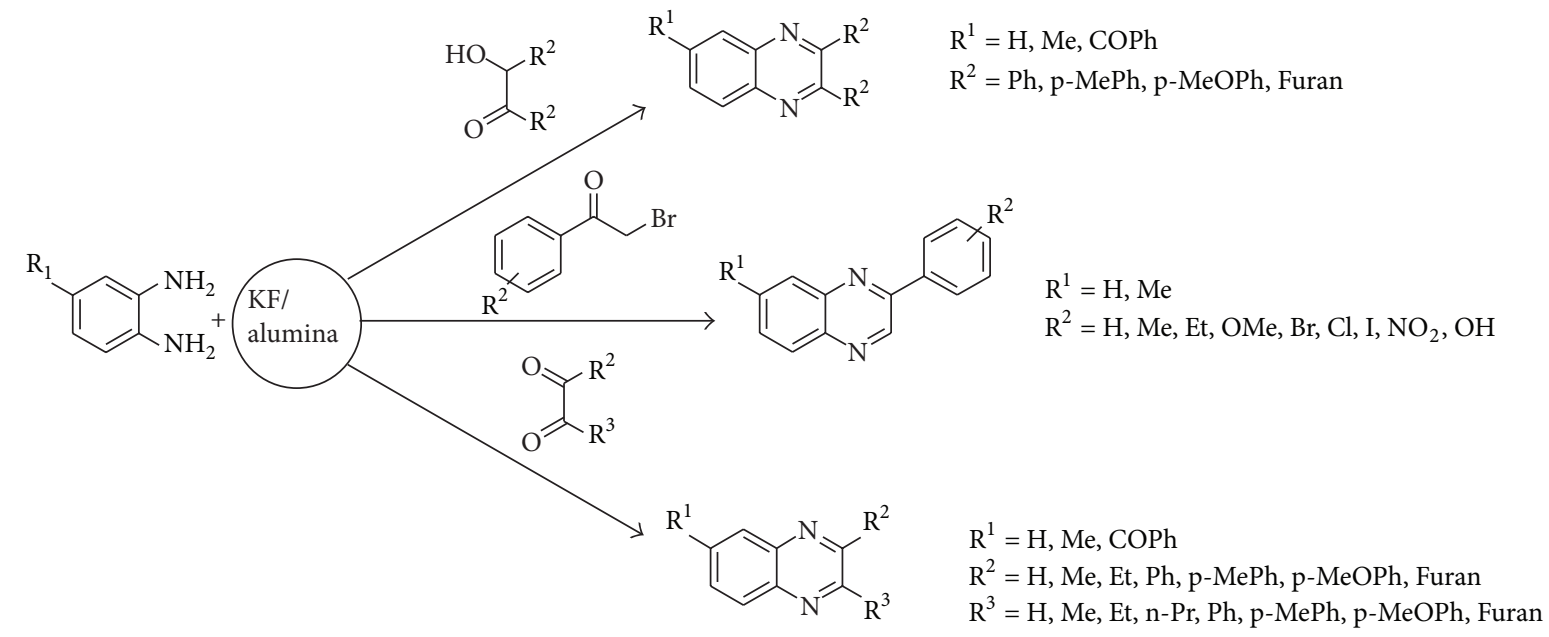

SCHEME 6

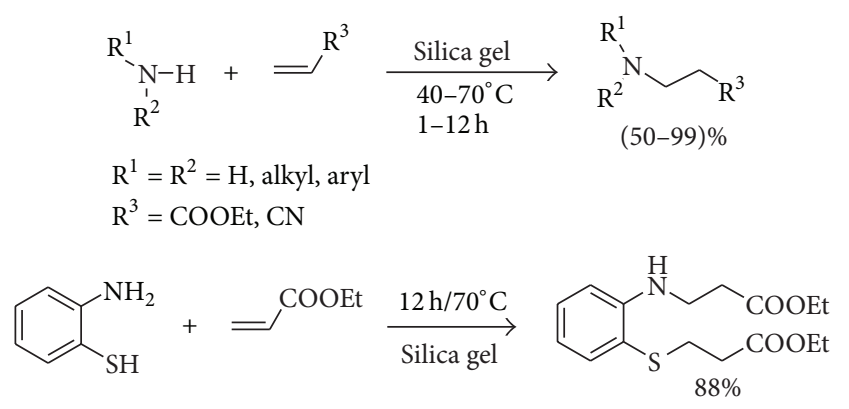

SCHEMe 7

base and other harsh conditions greatly limit providing a practical, generalized, and selective procedure. In continuation to explore organic reactions using solid surfaces, a highly selective procedure for mono- and bis-alkylations has been developed via $N$-alkylation of amines with alkyl halides in solid phase using silica at room temperature (Scheme 8) [114]. The procedure is simple and extremely useful for the control of the mono-, bis-, or overalkylations by varying the reaction conditions and molar proportions of amines and alkyl halides. The selectivity for mono- or bis-alkylations greatly depends on temperature, time of the reaction, proportion of the reactants, and also partly on the type of silica gel. Inactivated alkyl halides reacted with anilines to produce preferably the monoalkylated anilines in major quantities, even after using excess alkyl halide and continuing the reaction for prolonged time. The method was applied successfully to aliphatic bis-amine such as ethylene diamine and reaction with benzyl chloride or allyl bromide afforded the desired tetra-alkylated product in 73$79 \%$ yields. Selectivity of mono- and bis-alkylations under different conditions has been further broadened to synthesize unsymmetrical trialkyl/aryl amines (Scheme 8). The silica gel, after purification and activation, can be reused for ten consecutive runs (tested) without any substantial reduction in the yield as is observed from the recycling experiment.
TABLE 1: Reaction of thiophenol with acetyl chloride on various inorganic solid supports.

\begin{tabular}{lcc}
\hline Solid support $^{\mathrm{a}}$ & Time (min.) & \% Acetylation \\
\hline Silica & 120 & 92 \\
Neutral alumina & 120 & 64 \\
Bentonite & 30 & 56 \\
Mol. Sieves, $4 \AA$ & 120 & 20 \\
Talc & 60 & 39 \\
Neat & 120 & Nil \\
\hline
\end{tabular}

${ }^{a}$ Solid supports used $200 \mathrm{mg} \mathrm{mmol}^{-1}$; b yield by HPLC analysis along with another product (disulfide) and unreacted thiophenol.

3.3. S-Acylation and Alkylation of Thiols. Acylation and alkylation of thiols are essential transformations in organic synthesis and often used for protection of thiols and are also known in several biological phenomena [115-119]. SAcylation is the posttranslational attachment of fatty acids to cysteine residues [120]. S-Acylated peptides have many potential uses for elucidating the biophysical, structural, and other properties of numerous $S$-acylated proteins of mammalian cells $[121,122]$. On the other hand, thioethers are useful class of organic compounds and find versatile applications as key reagents in organic synthesis, bioorganic, heterocyclic, and medicinal chemistry. The promising solvent-free and highly selective $N$-alkylation promoted by silica gel has prompted to investigate $S$-alkylation and $S$ acylation reactions. Initial studies revealed that the reaction between thiophenol and acetyl chloride could be achieved at room temperature when stirred with silica gel under solventfree conditions producing S-phenyl ethanethioate in $93 \%$ yield. Neither acetic anhydride nor acetic acid was found to be effective for a similar conversion. Silica gel was also found to be a much better choice for promoting the $S$-acetylation reaction, while neutral alumina yielded the thioester in $64 \%$ yield, and bentonite or molecular sieves afforded considerable amounts of disulfide (Table 1). 


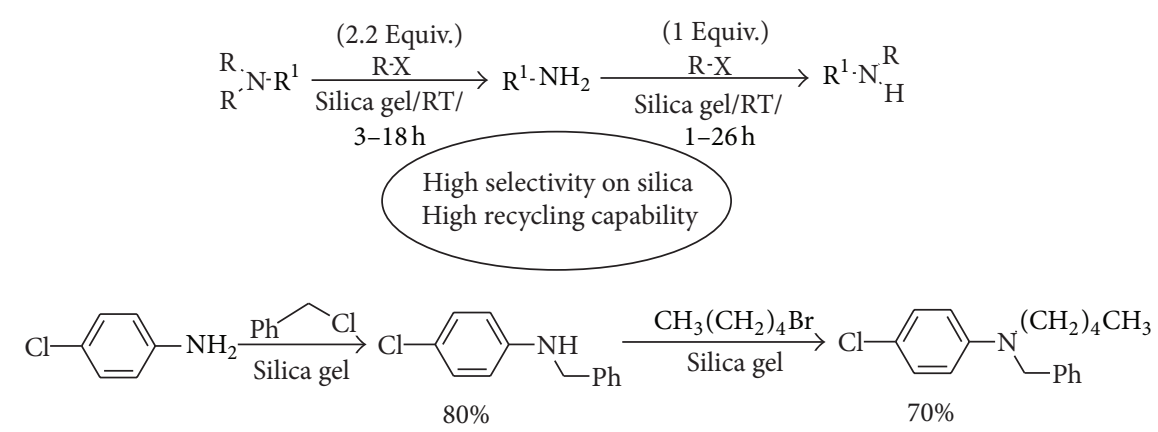

SCHEMe 8

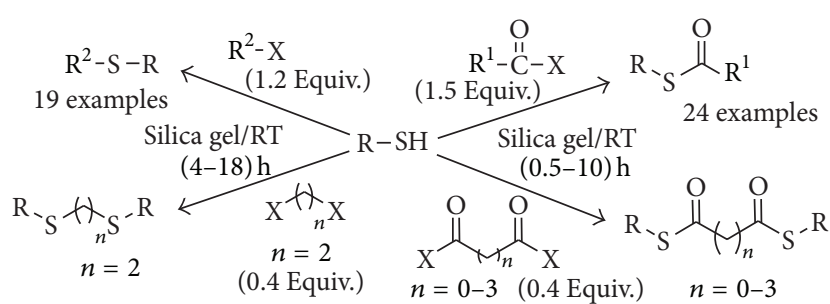

SCHEMe 9

Further attempts have been made to obtain general and efficient conditions for the $S$-acylation and $S$-alkylation reactions of several aromatic and aliphatic thiols with different acid chlorides and activated alkyl halides, respectively, in the presence of silica gel (Scheme 9). A smooth conversion was observed in each case, affording the desired products in good to excellent yields. Moreover, it was found that the recovered silica can be reused for seven consecutive runs, without any appreciable loss of activity [123].

\subsection{Selective Synthesis of 1,2-Disubstituted Benzimidazoles.} Functionalized benzimidazoles represent an important class of $\mathrm{N}$-containing heterocyclic compounds and have received considerable attention in recent times because of their vast applications as antiulcer, antihypertensive, antiviral, antifungal, anticancer, and antihistamines among others and also act as ligands for complexation with transition metals which are used for modeling biological systems [124-127]. Several synthetic strategies have been developed for the preparation of functionalized benzimidazoles [128-140].

Synthetic methods for 1,2-disubstituted benzimidazoles 3 often are associated with cooccurrence of several side reactions and by-products as shown in Scheme 10.

An efficient, simple protocol has been developed for highly selective synthesis of 1,2-disubstituted benzimidazole 3, catalyzed by iron(III) sulfate supported on silica at ambient temperature under solvent-free conditions (Scheme 11) [141]. Silica-supported iron catalysts have been prepared and used in affecting various organic reactions [142-148]. Aldehydes bearing different functional groups as well as heteroaryl aldehydes reacted smoothly with $o$-PDs leading to the formation of corresponding 1,2-disubstituted benzimidazoles with complete selectivity and in good to excellent yields. No electronic or steric impact was found to be prominent in the selective formation of 3 .

Although the exact mechanism is not clear, the Lewis acid-mediated mechanism is expected to play (Figure 2). Adsorption of iron(III) sulfate on the surface of silica is believed to make polynuclear iron(III) hydroxyl complexes 4 [149]. Silica being a water absorbent could facilitate formation of the bis-Schiff base 5, which has been reported and indeed was isolated when the reaction was stopped after $20 \mathrm{~min}$. The Schiff base 5 may undergo cyclization followed by 1,3hydride shift induced by electrophilic catalyst [150], resulting in the formation of the 1,2-disubstituted benzimidazole 3 . An indirect evidence in favour of 1,3-hydride shift of the Schiff base 5 , isolated from $o$-phenylenediamine and salicylaldehyde (6), showed reluctance to undergo cyclization at room temperature. This is possibly because of intramolecular $\mathrm{H}$-bonding with $\mathrm{o}-\mathrm{OH}$ group [151], making the nitrogen less nucleophilic, and thus required higher temperature for the cyclization (Scheme 12). The existence of intramolecular hydrogen bonding in the Schiff base (6) was also demonstrated by ${ }^{1} \mathrm{H}-\mathrm{NMR}$ studies at varying concentrations of the Schiff base (6) [141].

\section{Reactions on Organic Polymer Support}

The polymeric supports used by Merrifield for his early work in solid-phase peptide synthesis were based on $2 \%$ divinylbenzene (DVB) cross-linked polystyrenes (PS). PS has been found to be one of the most accepted polymeric material used in various synthesis because it is inexpensive, readily available, mechanically robust, chemically inert, and smoothly functionalizable [152, 153]. Crosslinking imparts mechanical stability, improved diffusion and swelling properties to the resin. Various percentages and types of crosslinking agents have been incorporated into the PS resins, the most common being DVB, but other examples include ethylene glycol dimethylacrylate (EGDMA) and tetraethylene glycol diacrylate (TEGDA) to give different solvation properties $[154,155]$. A schematic representation of polymerization of styrene with functionalized monomers is shown in Figure 3.

TentaGel [156] and ArgoGel [157] (Figure 4) are two commercially available examples, where the incorporation of the PEG chains dramatically increases resin compatibility with polar solvents. 


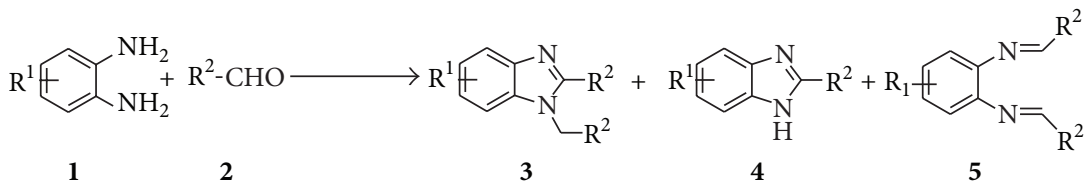

SCHEME 10

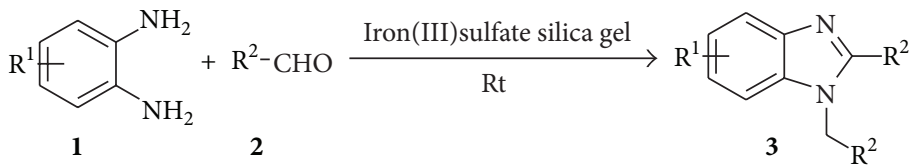

SCHEME 11

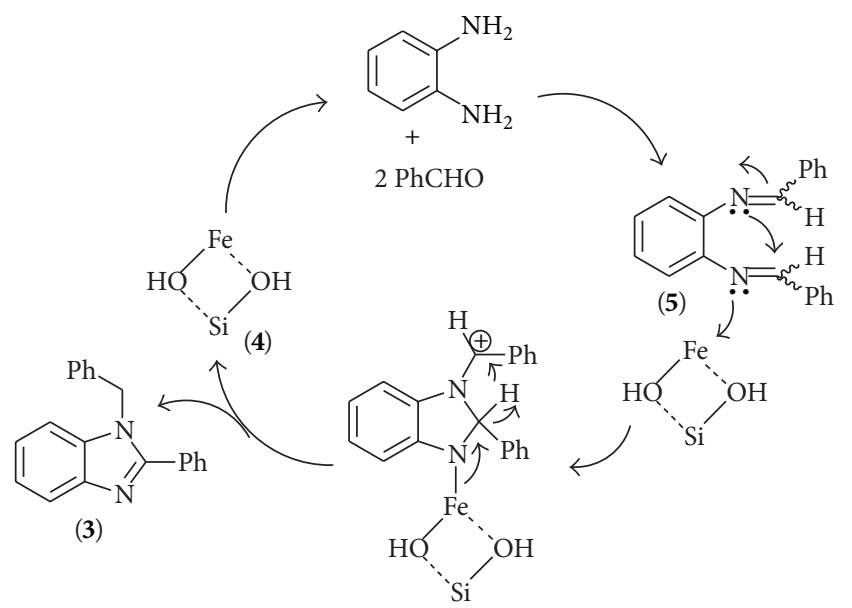

FIGURE 2

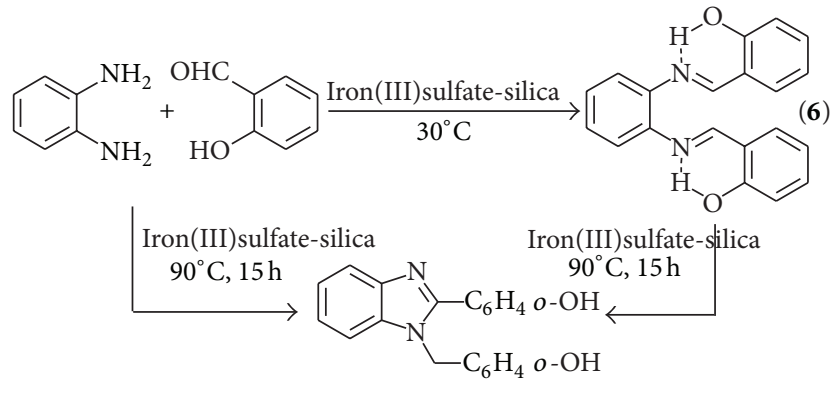

SCHEME 12

Generally, reagents and catalysts are immobilized onto polymer surface involving (i) covalent binding, (ii) entrapment, where a preformed catalyst is enveloped within a polymer network, and (iii) ion-pairing, where cations or anions are bound to complementary resin sites [158]. Immobilization of reagents and catalysts can also be done by microencapsulation [159], where the polymers are physically enveloped by thin films of reagents or catalysts, and perhaps stabilized by the interaction between $\pi$ electrons of benzene rings of the polystyrene used as a polymer backbone and vacant orbital of reagents or catalysts [160].
4.1. Catalytic Transfer Hydrogenation (CTH) Using Supported Formate. Catalytic transfer hydrogenation $(\mathrm{CTH})$ with the aid of a stable hydrogen donor is a useful alternative method to catalytic hydrogenation using molecular hydrogen $\left(\mathrm{H}_{2}\right)$ [161-166]. In transfer hydrogenation, several organic molecules such as hydrocarbons, primary and secondary alcohols, and formic acid and its salts have been employed as the hydrogen source [167-173]. The use of reagents such as hydrazine is less frequent. The use of a hydrogen donor has some advantages over the use of molecular hydrogen, since it avoids the risks and the constraints associated with hydrogen gas as well as the necessity for using pressure vessels and other equipment.

4.1.1. Palladium-Catalyzed Transfer Hydrogenation (CTH) of Alkenes and Imines. In connection with our interest in palladium-catalyzed transfer hydrogenation $(\mathrm{CTH})$ of alkenes and imines using potassium formate [82], we wanted to develop a stable hydrogen donor anchored to a solid surface to be used in CTH (Figure 5). In search of suitable polymeric supports, ion-exchange resins were used. It was observed that Amberlite IRA-420 anion (chloride form) exchange resins, commercially available and inexpensive polyionic resin, could exchange the anion with formate anion $\left(\mathrm{HCOO}^{-}\right)$easily and quantitatively. The resulting Amberlite Resin Formate (anion), designated as ARF, could be utilized as a solid-phase version of the $\mathrm{H}$-donor in Pd-catalyzed CTH. The ARF was air stable, can be stored for several weeks, and also can be recovered from a reaction and reused. Several alkenes and imine were thus hydrogenated using the ARF and catalytic amount of palladium acetate under mild conditions (Scheme 13) [174].

The reduction of the $\mathrm{C}-\mathrm{C}$ double bond proceeded smoothly at $70-75^{\circ} \mathrm{C}$ requiring only gentle agitation; workup was then achieved by simple filtration, extraction with diethyl ether and followed by evaporation of the solvent. Both the cyano and ester groups remained unaffected under the reaction conditions. The reduction of a dicyanoalkylidene derivative was found to occur with similar efficiency. The method is operationally simple and applicable to a variety of unsaturated organic compounds. The use of a palladium catalyst exhibits some substrate selectivity, and the transfer 


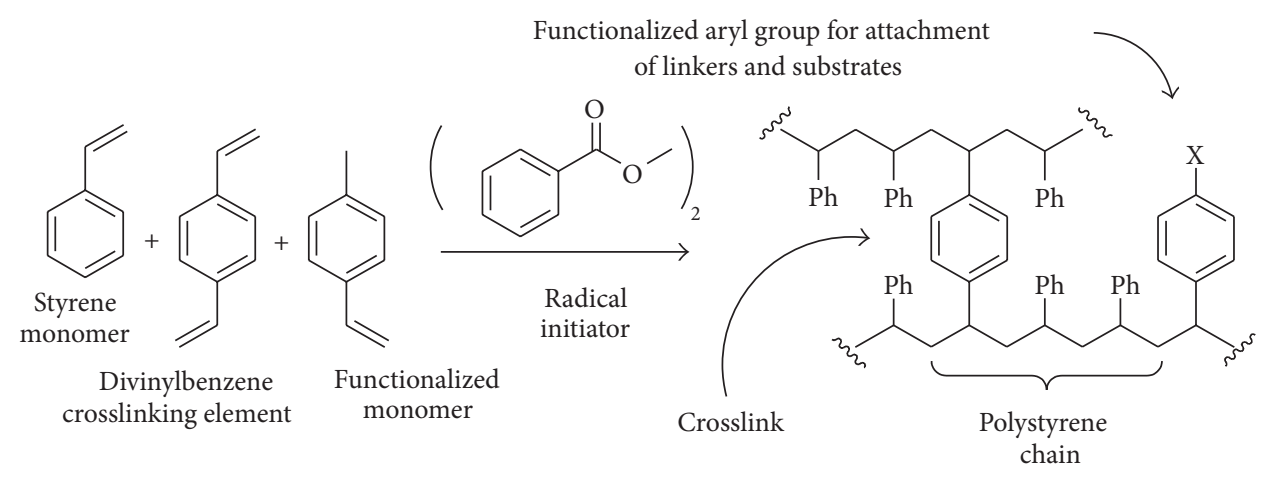

Figure 3

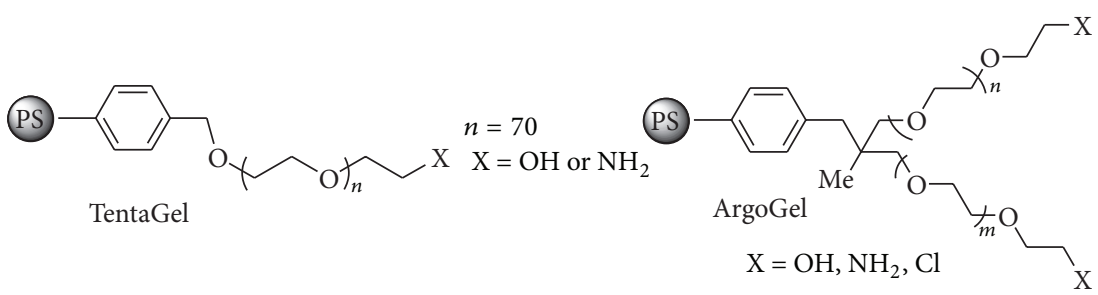

FIGURE 4

hydrogenation appears to proceed at a slower rate in comparison to that of potassium formate.

4.1.2. Palladium-Catalyzed Transfer Hydrogenation (CTH) of Nitroarenes. With the success of reducing $\mathrm{C}-\mathrm{C}$ and $\mathrm{C}-\mathrm{N}$ bonds using the solid-supported formate as suitable $\mathrm{H}$-donor [174], further attempts have been made in the reduction of nitroarenes to anilines, which is a synthetically important transformation both in the laboratory and in industry. Formic acids and their salts are frequently employed as $\mathrm{H}$-donor in CTH reactions, and nitroarenes can be reduced to anilines using ammonium formate and Pd-C or Raney nickel [175177]. However, reductive elimination of halogen substituents on the aromatic nucleus and formation of $N$-formyl derivatives instead of arylamines are the major drawbacks of using ammonium formate/Pd-C. On the other hand, combination of $\mathrm{NaBH}_{4}$ with $\mathrm{Cu}$ (II), $\mathrm{Co}(\mathrm{II})$, or $\mathrm{Rh}$ (III) halides has been used for reduction of the nitro group, which is inert to $\mathrm{NaBH}_{4}$ itself $[178,179]$. Metal hydrides are, however, water-sensitive as well as expensive chemicals. The reduction of nitro group was carried out using $2 \mathrm{~mol} \% \mathrm{Pd}(\mathrm{OAc})_{2}$ and (aminomethyl) polystyrene with formate anion (ARF) in a minimum quantity of DMF at $100-120^{\circ} \mathrm{C}$ for 6-14 h (Scheme 14) [180].

\subsubsection{Ruthenium-Catalyzed Transfer Hydrogenation (CTH)} of Carbonyl Groups. Reduction of carbonyl functionality by transition metal-catalyzed transfer hydrogenation $(\mathrm{CTH})$ with the aid of a suitable $\mathrm{H}$-donor is a valuable synthetic tool. Generally, reduction of aryl ketones is performed under CTH using isopropyl alcohol as the H-donor [181186]. In order to check the efficiency of Amberlite Resin Formate (ARF), reduction of aryl ketones was studied using the combination of catalytic amount of $\mathrm{Ru}(\mathrm{III})$ salts and the polyionic resin formate. The results constitute an efficient method for chemoselective transfer hydrogenation of aryl aldehydes with the aid of resin-supported formate in the presence of catalytic ( $2.5 \mathrm{~mol} \%)$ amount of commercially available $\mathrm{RuCl}_{3} \cdot 3 \mathrm{H}_{2} \mathrm{O}$ in DMF or DMA solution, as outlined in Scheme 15 [187].

On the basis of comparison with a well-defined $\mathrm{Ru}(\mathrm{II})$ complex [Dichloro(p-cymene)ruthenium(II)] dimer; (2 mol $\%)$ under similar conditions, it is presumed that the $\mathrm{Ru}(\mathrm{III})$ salt might undergo in situ reduction to $\mathrm{Ru}(\mathrm{II})$, which then catalyzes the hydrogenation of the aldehydes. Aryl and heteroaryl aldehydes, substituted with various electron withdrawing and donating groups and the presence of $o$ substituents, do not seem to influence the rate of the reduction as revealed by the similarity of the results, and all compounds afford corresponding alcohols in high yields. Several other potential reducible groups like halogens, nitro, and so forth are not affected under the reaction conditions. Aliphatic aldehydes are also reduced to corresponding alcohols efficiently. Interestingly, aryl ketones are not reduced under similar conditions. The selectivity between aryl aldehyde and aryl ketone might offer a distinct advantage when both the functional groups are present. Thus, an experiment was conducted taking a mixture of an aryl aldehyde and an aryl ketone ( $1 \mathrm{mmol}$ each $)$ at $85^{\circ} \mathrm{C}$ to finally afford the reduced alcohol from the aryl aldehyde, but the aryl ketone remained unchanged and recovered almost quantitatively. Whereas aryl ketones are not reduced under the conditions, reduction of benzil to benzoin proceeds smoothly in good to excellent yields. Distinct advantages of cleaner reaction and easy isolation of the product are notable features when comparing the application of heterogeneous ARF and a simple formate salt (herein potassium formate) in homogeneous phase. 


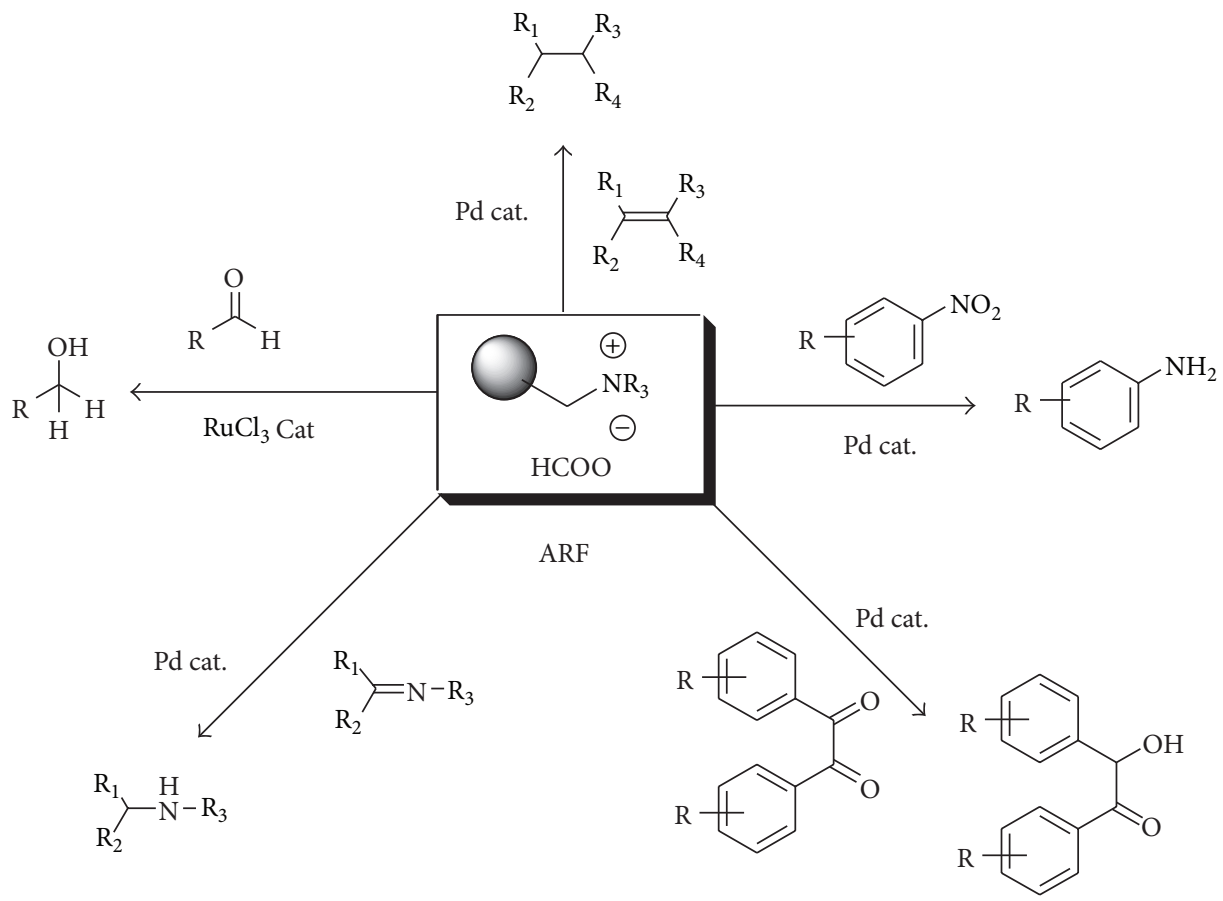

Figure 5

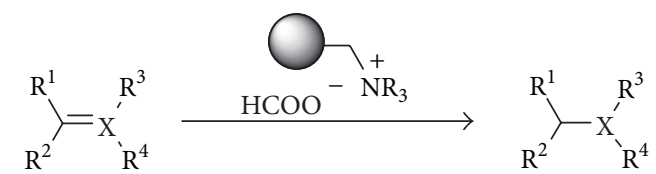

$\mathrm{R}^{1}=\mathrm{R}^{2}=\mathrm{Ph}, \mathrm{Ar}, \mathrm{H}$

$\mathrm{R}^{3}=\mathrm{R}^{4}=\mathrm{CN}$, COOEt, COOMe, NHBoc, $\mathrm{H}, \mathrm{Ph}$

$\mathrm{X}=\mathrm{C}, \mathrm{N}$

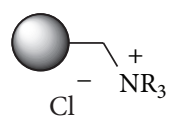

Amberlite IRA-420

Chloride form taken in water
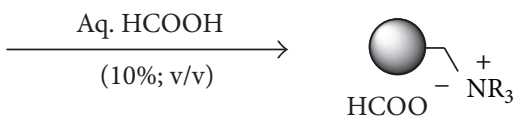

Amberlite IRA-420 Formate form
SCHEMe 13<smiles>[R]c1ccc(N)cc1</smiles>

SCHEME 14

The reaction conditions appear to be mild and base-free and give high yields of the corresponding alcohols and free of any by-product.

4.1.4. Catalytic Transfer Hydrogenation (CTH) Using Coimmobilized Catalyst/Reagent. It is well established that $\mathrm{Pd}$ promotes direct oxidation of formic acid to carbon dioxide
[173]. The combination of formic acid and palladium acetate is known to undergo anionic ligand exchange to form a palladium diformate complex, eventually producing $\mathrm{Pd}(0)$ through decarboxylation and loss of molecular hydrogen. The high degree of chemoselectivity in palladium-catalyzed transfer hydrogenation using $\mathrm{HCOOH}$ or its salts has been explained on the basis that the hydrogen is delivered directly from a palladium formate species, which has much stronger hydridic nature as compared to that of a palladium hydride species (Scheme 16).

In $\mathrm{CTH}$, either a source of palladium is required for each operation or it may be supported by a polymer framework and reused several times. It is reasoned that the palladium catalyst might be anchored to the ARF so that it could be used and recycled (Scheme 17). It is observed that palladium can be immobilized onto the polyionic resins surface and used efficiently in the CTH of a variety of functional groups. Thus, a new solid-phase entity (ARF-Pd) has been developed coimmobilizing both the catalyst and the reagent and expected to be potentially useful in CTH of different functional groups.

The efficiency and stability of this newly developed ARF$\mathrm{Pd}$ was first examined in the reduction of electron-deficient alkenes conjugated with ketones, nitriles, and carboxylate esters (Scheme 18) [188]. Further applications of this new heterogeneous reductive system are tested with 1,2-dicarbonyl compounds. When benzil or substituted benzil is used as the substrate, the reduction of one of the carbonyl groups with ARF-Pd in DMF at $110^{\circ} \mathrm{C}$ has been completed within 10$12 \mathrm{~h}$ to furnish the corresponding $\alpha$-hydroxyketone (benzoin) in a $77-88 \%$ yield. Aromatic nitro compounds are also reduced using the coimmobilized palladium in DMF. This new technique is highly chemoselective in the reduction 


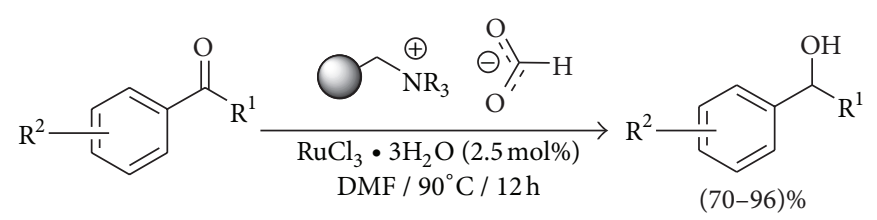

$\mathrm{R}^{1}=\mathrm{H}, \mathrm{COAr}$

$\mathrm{R}^{2}=\mathrm{H}$, Alkyl, Br, $\mathrm{Cl}, \mathrm{F}, \mathrm{NO}_{2}$, OMe, OAr

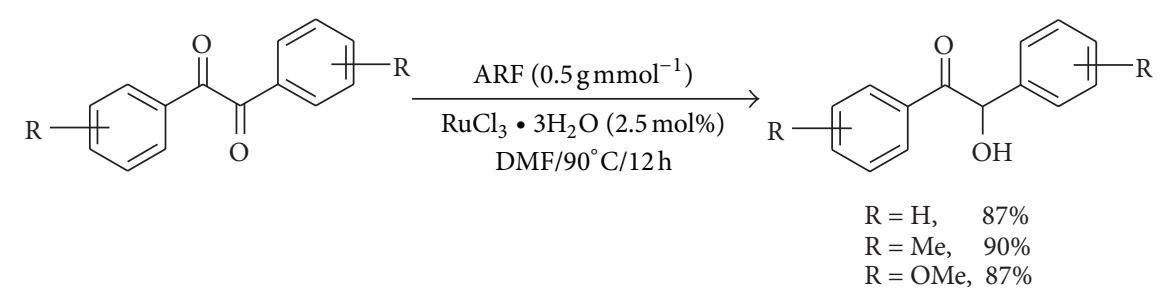

SCHEMe 15

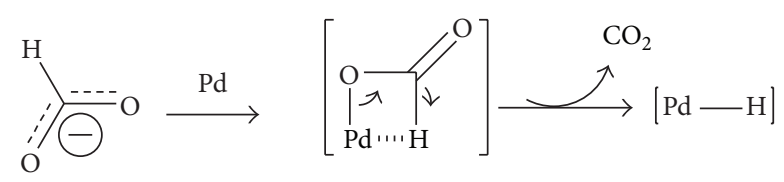

SCHeme 16

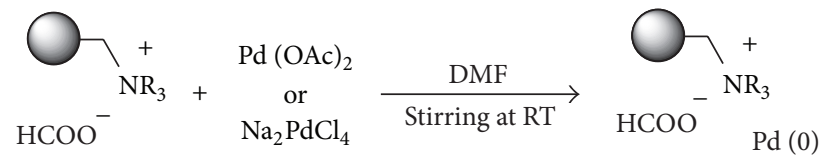

SCHEMe 17

of alkenes, imines, and nitro groups, thus establishing an efficient, environmentally benign, economically friendly, and sustainable process.

4.2. C-C Cross-Coupling Reactions. Transition metal-catalyzed cross-coupling reactions constitute the central part of contemporary organic synthesis [189-192]. In particular, the palladium-catalyzed carbon-carbon bond-forming processes represent the foremost in the arena of organic process development. The Heck, Suzuki-Miyaura, Sonogashira reactions (Scheme 19) are excellent tools for carbon-carbon coupling reactions between aryl halides or triflates and suitable partners [193].

The coupling of terminal alkynes with an aryl or vinyl halide performed with a palladium catalyst, a copper cocatalyst and an amine base, is termed as the Sonogashira coupling reaction [194-206]. Typically, the reaction requires anhydrous and anaerobic conditions, but the newer procedures which have been developed show that the restrictions are not so important.

Over the last decade, commendable research has been done to achieve significant developments and to establish practical methodologies [207-210]. Widespread uses of palladium-catalyzed coupling reactions are found in modern organic synthesis, because the resulting coupled products often find good applications in the preparation of materials, pharmaceuticals, and other bioactive compounds [211-218]. As a part of recognition of these extremely useful reactions, Nobel prize was awarded to Heck, Suzuki, and Negishi [219]. Many efforts have been reported to immobilize Pd, using a support, encapsulating in a polymer or dendrimer or immobilization by ligand/polymer, but the problem of leaching and recyclability still exists [220-236].

4.2.1. Use of ARF-Pd in C-C Cross-Coupling Reactions. Excellent activity, high selectivity, and reusability of the ARF-Pd as potential reductive system have prompted to explore it as a viable heterogeneous $\mathrm{Pd}$ catalyst in various $\mathrm{C}-\mathrm{C}$ coupling reactions (Scheme 20) [237]. One of the key questions on which the researchers have focused is "how can minimization of catalyst cost and catalyst contamination of the product be best achieved?" It may be noted that the investigation of the heterogeneous ARF-Pd has addressed a great extent to this question.

The catalytic activity of ARF-Pdwas first examined in the Heck coupling reactions and then for the Suzuki and Sonogashira reactions, as outlined in Scheme 20.

Indeed the Heck coupling between 3-chloroiodobenzene and ethyl cinnamate in the presence of the heterogeneous catalyst ARF-Pd, the cross-coupled product, trans-ethyl-3-chlorocinnamate, has been isolated in $86 \%$ yield. Exclusive transselectivity is achieved, as is assigned on the basis of the coupling constant $(J=15.9 \mathrm{~Hz})$. Although several iodoarenes undergo Heck coupling with an alkene, interestingly, the bromoarenes remain unchanged which is typically seen for other halogens like chloro or fluoro groups attached with the aromatic moiety. The ortho-substituent did not cause any steric inhibition, as usually experienced in other coupling reaction, which may be attributed to high activity of the catalyst.

The Suzuki-Miyaura reaction (Scheme 20) has been carried out using 4-bromo-2-methyl anisole, phenyl boronic acid, $\mathrm{Na}_{2} \mathrm{CO}_{3}$ in the presence of ARF-Pd. Heating the mixture at $110^{\circ} \mathrm{C}$ for $5 \mathrm{~h}$ under $\mathrm{N}_{2}$ followed by removal of ARFPd by simple filtration and chromatographic purification of 


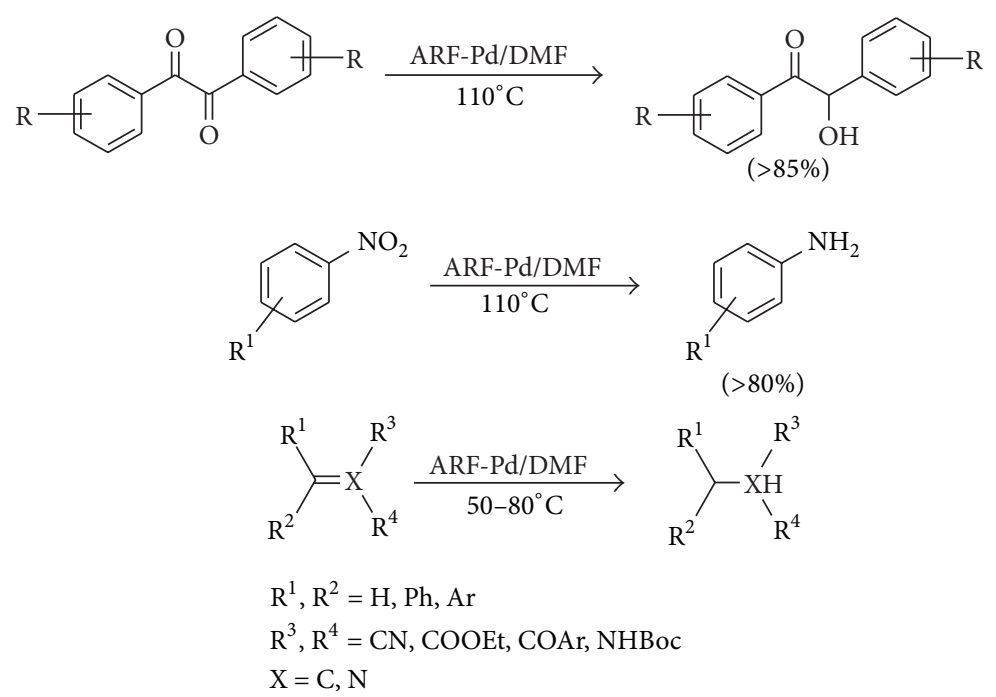

SCHEMe 18
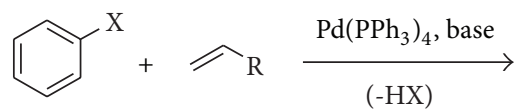<smiles>[R]C=Cc1ccccc1</smiles><smiles>[R]c1cccc(B(O)O)c1[R]</smiles><smiles>[R]c1cccc(-c2ccccc2)c1</smiles><smiles>[R]C#C[In]c1ccccc1</smiles><smiles>CC(C)(C)C(=N)c1ccccc1</smiles><smiles>[R]C#Cc1ccccc1</smiles>

SCHeme 19

the residual mixture furnished the desired unsymmetrical biphenyl in $82 \%$ yield. Both bis- and tris-coupled aryl benzenes have also been prepared in good to excellent yields when reactions are performed using di- and tribromoarenes, respectively, showing notable activity of the heterogeneous palladium catalysts (ARF-Pd). It may be noted that orthodibromobenzene affords a mixture of mono- and biscoupled products in the presence of $\mathrm{Pd}(\mathrm{OAc})_{2}$ as the source of palladium.

The Sonogashira coupling reaction normally requires 1$10 \mathrm{~mol} \% \mathrm{Pd}\left(\mathrm{PPh}_{3}\right)_{2} \mathrm{Cl}_{2}\left(\right.$ or $\left.\mathrm{Pd}\left(\mathrm{PPh}_{3}\right)_{4}\right)$ and copper(I) iodide as the catalytic system. Using the ARF-Pd, the reaction of 3-iodoanisole and 1-ethynyl-4-methylbenzene carried out in the presence of $\mathrm{Et}_{3} \mathrm{~N}$ as the base in acetonitrile solvent at $80^{\circ} \mathrm{C}$ for $6 \mathrm{~h}$ afforded the desired cross-coupled product in excellent yield (Scheme 20). Similar coupling reactions with other iodoarenes and acetylenes are also found to be successful [237].

In all cases, products are isolated in pure form simply by filtering off the resin-bound palladium catalyst followed by chromatographic purification of the concentrated residue. Recycling experiments are tested by taking Suzuki-Miyaura coupling between 1,4-dibromobenzene and phenylboronic acid. The results have revealed that the catalyst is remarkably active even in the fifth run. Consecutive five runs were tested to evaluate the activity of ARF-Pd. The palladium content throughout the recycling runs remained at a steady state with marginal increase of $\mathrm{Pd}$ distribution on the resin surface, which might be due to repeated agitation of the beads during the reactions and exposing more surface area with palladium content.

\subsubsection{Suzuki Coupling Using Solid-Phase Immobilized} Organoboron Species. The concept of a resin-capture-release technique generating the polymer-bound reactive species has been established as a potential method for several organic transformations [238-240]. A variety of techniques are reported in the literature to immobilize different components of Suzuki cross-coupling reaction [241-253]. Polymer-bound boronic acids though reported as early as 1976 [254], Frenette and Friesen [255] investigated their utility in Suzuki coupling reaction in 1994.

Further application of polyionic resin bound reagents and/or catalysts has been established when an ion-exchange resin-supported organoborate species is derived as a heterogeneous phenylating agent [256]. Thus, Amberlite ion-exchange resins (chloride form) are exchanged with tetraphenylborate anion $\left(\mathrm{Ph}_{4} \mathrm{~B}^{-}\right)$by continuous rinsing with an aqueous solution of $\mathrm{NaBPh}_{4}$ until the washings gave negative response to chloride anion (monitored with $\mathrm{AgNO}_{3}$ solution followed by addition of aqueous ammonia). The polyionic resins with the tetraphenylborate counter anion $\left(\mathrm{Ph}_{4} \mathrm{~B}^{-}\right)$have been used directly for the Suzuki coupling reaction. Initial studies on coupling with 3-iodotoluene in the presence of palladium catalyst $\left[\mathrm{Pd}(\mathrm{OAc})_{2} ; 2 \mathrm{~mol} \%\right.$ and $\mathrm{Na}_{2} \mathrm{CO}_{3} ; 1$ equiv.] afford the unsymmetrical biphenyl in $90 \%$ yield (Scheme 21, condition (a)). Similar coupling of 3iodotoluene and $\mathrm{NaBPh}_{4}$ in the presence of $\mathrm{Na}_{2} \mathrm{CO}_{3}$ afforded only $43 \%$ yield of the coupled product (Scheme 21 , condition (b)). However, on increasing the quantity of $\mathrm{NaBPh}_{4}$, the resulting coupled product could be isolated in $88 \%$ yield 

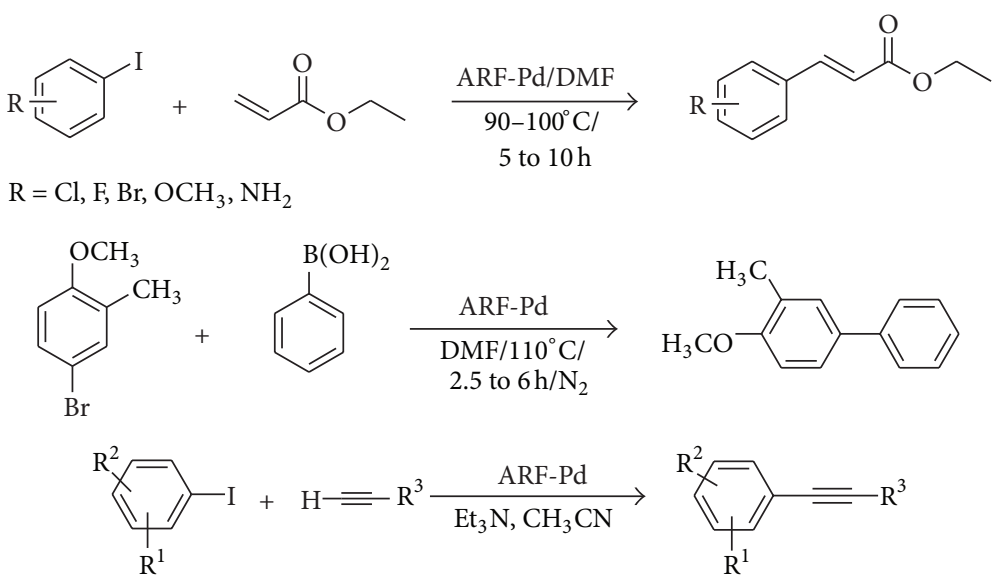

$\mathrm{R}^{1}, \mathrm{R}^{2}=\mathrm{OMe}, \mathrm{Me}, \mathrm{Br}$

SCHEME 20

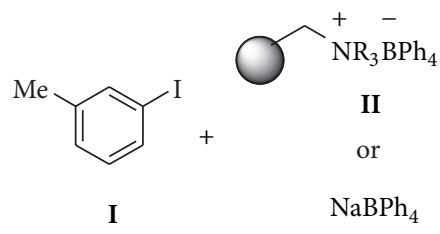

III

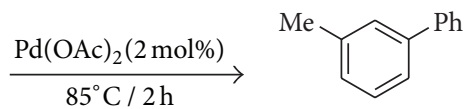

Conditions:

(a) $\mathrm{I} / \mathrm{II} / \mathrm{Na}_{2} \mathrm{CO}_{3}=1: 1 \mathrm{~g} / \mathrm{mmol}: 1 ; 9 \%$

(b) $\mathbf{I} / \mathrm{III} / \mathrm{Na}_{2} \mathrm{CO}_{3}=1: 1: 1 ; 43 \%$

(c) $\mathrm{I} / \mathrm{III} / \mathrm{Na}_{2} \mathrm{CO}_{3}=1: 2.5: 1 ; 88 \%$

(d) $\mathrm{I} / \mathrm{III}=1: 2.5 ; 88 \%$

(e) $\mathbf{I} / \mathbf{I I}=1: 1 \mathrm{~g} / \mathrm{mmol} ; 96 \%$

SCHEME 21

(Scheme 21, condition (c)). An interesting observation is that the yield of the coupled product is not influenced by the absence of base (Scheme 21, conditions (d) and (e)). Such base-free conditions for SM reactions could offer significant practical advantages and have not previously been reported with the organoborate ion bound with solid-phase polymeric frameworks.

4.2.3. Organic Disulfide (S-S Linkage) Synthesis. Organic disulfides (bearing S-S linkage) are useful compounds of widespread occurrence possessing unique and diverse chemistry in the synthetic, biochemical, and agrochemical areas [257-259]. Disulfide-linked aggregates ubiquitously occur in proteins and many other bioactive molecules. Disulfide bonds play an important role in the folding and stability of some proteins $[260,261]$. Industrially, disulfides find vast applications as vulcanizing agents for rubbers and elastomers, contributing them considerable tensile strength [262, 263]. Apart from various solution-phase approaches for the synthesis of disulfide from thiols and other precursors, there are few reports on the synthesis of disulfides promoted by polymeric resin hydroxides. In a recent report, Sengupta and Basu have shown that Amberlyst A-26(OH) can efficiently promote smooth conversion of disulfides from alkyl and acyl methyl thiocyanates in good to excellent yields (Scheme 22). They have also demonstrated that the use of polyionic resin hydroxide has resulted in much better results over other homogeneous bases like $\mathrm{NaOH}, \mathrm{NH}_{3}, \mathrm{~K}_{2} \mathrm{CO}_{3}$ [264].

\section{Conclusion}

Thus, a series of reactions has been developed exhibiting the potential of using both inorganic and organic polymeric frameworks as the solid phase. The present review has shown that alumina, silica surface alone or having doped with various inorganic salts could be utilized in carrying out different organic reactions under solvent-free conditions producing molecules of biological and industrial importance. Similarly, polyionic resins have been shown to immobilize reagents and/or catalysts and employ in transfer hydrogenation of alkenes, imines, and nitroarenes and in different $\mathrm{C}-\mathrm{C}$ crosscoupling reaction. Mild reaction conditions, easy work-up procedure, selective synthesis of the target molecules, and recycling capability of the supported reagent or catalyst are some of the advantages of adopting solid-phase organic reactions. Further development of newer solid phases, immobilization procedures resulting in regular dispersion and finally their new applications are expected in the years to come. 


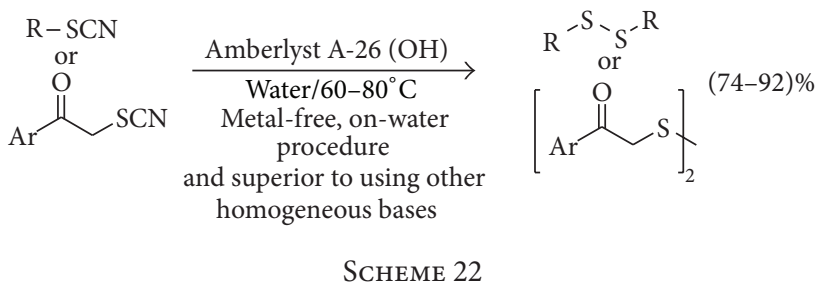

\section{Acknowledgments}

The author Basudeb Basu wishes to thank all the contributors from this research group, whose names are in their respective publications mentioned in the reference section. Financial support from the Department of Science and Technology, India, is gratefully acknowledged, including the ongoing Grant no. SR/S1/OC-86/2010.

\section{References}

[1] R. B. Merrifield, "Solid phase peptide synthesis. I. The synthesis of a tetrapeptide," Journal of the American Chemical Society, vol. 85, no. 14, pp. 2149-2154, 1963.

[2] G. H. Posner, "Organicreactions at alumina surfaces," Angewandte Chemie-International Edition, vol. 17, no. 7, pp. 487496, 1978.

[3] A. McKillop and K. W. Young, "Organic synthesis using supported reagents-part I \& part II," Synthesis, pp. 401-422, 481$500,1979$.

[4] A. Cornelis and P. Laszlo, "Clay-supported copper(II) and iron(III) nitrates: novel multi-purpose reagents for organic synthesis," Synthesis, no. 10, pp. 909-918, 1985.

[5] P. Laszlo, Preparative Chemistry Using Supported Reagents, Academic Press, San Diego, Calif, USA, 1987.

[6] E. K. Smith, Solid Supports and Catalyst in Organic Synthesis, Ellis Horwood, Chichester, UK, 1992.

[7] M. Balogh and P. Laszlo, Organic Chemistry Using Clays, Springer, Berlin, Germany, 1993.

[8] J. H. Clark, Catalysis of Organic Reactions by Supported Inorganic Reagents, VCH, New York, NY, USA, 1994.

[9] R. L. Letsinger and V. Mahadevan, "Oligonucleotide synthesis on a polymer support," Journal of the American Chemical Society, vol. 87, no. 15, pp. 3526-3527, 1965.

[10] J. M. Fraile, J. A. Mayoral, A. J. Royo et al., "Supported chiral amino alcohols and diols functionalized with aluminium and titanium as catalysts of Diels-Alder reaction," Tetrahedron, vol. 52, no. 29, pp. 9853-9862, 1996.

[11] A. P. T. Anastas and J. C. Warner, Green Chemistry: Theory and Practice, Oxford Science Publications, New York, NY, USA, 1998.

[12] P. T. Anastas and T. Williamson, Green Chemistry: Frontiers in Benign Chemical Synthesis and Procedures, Oxford Science Publications, New York, NY, USA, 1998.

[13] J. H. Clark, "Green chemistry: challenges and opportunities," Green Chemistry, vol. 1, no. 1, pp. 1-8, 1999.

[14] M. Lancaster, Green Chemistry: An Introductory Text, Royal Society of Chemistry, Cambridge, Mass, USA, 2002.

[15] G. W. V. Cave, C. L. Raston, and J. L. Scott, "Recent advances in solventless organic reactions: towards benign synthesis with remarkable versatility," Chemical Communications, no. 21, pp. 2159-2169, 2001.

[16] P. Hodge and D. C. Sherrington, Polymer-Supported Reactions in Organic Synthesis, John Wiley and Sons, Chichester, UK, 1980.

[17] P. Hodge and D. C. Sherrington, Syntheses and Separations Using Functional Polymers, John Wiley and Sons, Chichester, UK, 1988.

[18] A. Akelah and D. C. Sherrington, "Recent developments in the application of functionalized polymers in organic synthesis," Polymer, vol. 24, no. 11, pp. 1369-1386, 1983.

[19] J. A. Gladysz, "Introduction: recoverable catalysts and reagents-perspective and prospective," Chemical Reviews, vol. 102, no. 10, pp. 3215-3216, 2002.

[20] D. C. Sherrington, "Polymer-supported reagents, catalysts, and sorbents: evolution and exploitation-a personalized view," Journal of Polymer Science, Part A, vol. 39, no. 14, pp. 2364-2377, 2001.

[21] D. C. Sherrington, "Preparation, structure and morphology of polymer supports," Chemical Communications, no. 21, pp. 22752286, 1998.

[22] P. Wentworth and K. D. Janda, "Liquid-phase chemistry: recent advances in soluble polymer-supported catalysts, reagents and synthesis," Chemical Communications, no. 19, pp. 1917-1924, 1999.

[23] J. S. Yadav and H. M. Meshram, "Green twist to an old theme. An eco-friendly approach," Pure and Applied Chemistry, vol. 73, no. 1, pp. 199-203, 2001.

[24] M. Lebl, "Solid-phase synthesis on planar supports," Biopolymers, vol. 47, pp. 397-404, 1998.

[25] N. J. Maeji, R. M. Valerio, A. M. Bray, R. A. Campbell, and H. M. Geysen, "Grafted supports used with the multipin method of peptide synthesis," Reactive Polymers, vol. 22, no. 3, pp. 203-212, 1994.

[26] N. Hird, I. Hughes, D. Hunter, M. G. J. T. Morrison, D. C. Sherrington, and L. Stevenson, "Polymer discs-an alternative support format for solid phase synthesis," Tetrahedron, vol. 55, no. 31, pp. 9575-9584, 1999.

[27] R. C. D. Brown, "Recent developments in solid-phase organic synthesis," Journal of the Chemical Society, Perkin Transactions 1, no. 19, pp. 3293-3320, 1998.

[28] D. C. Sherrington, "Polymer-supported synthesis," in Chemistry of Waste Minimisation, J. H. Clark, Ed., chapter 6, Blackie Academic, London, UK, 1995.

[29] J. H. Clark, A. P. Kybett, and D. J. Macquarrie, Supported Reagents: Preparation, Analysis and Applications, VCH, New York, NY, USA, 1992.

[30] D. J. Gravert and K. D. Janda, "Organic synthesis on soluble polymer supports: liquid-phase methodologies," Chemical Reviews, vol. 97, no. 2, pp. 489-509, 1997.

[31] J. O. Metzger, "Solvent-free organic syntheses," Angewandte Chemie-International Edition, vol. 37, no. 21, pp. 2975-2978, 1998.

[32] M. S. Singh and S. Chowdhury, "Recent developments in solvent-free multicomponent reactions: a perfect synergy for eco-compatible organic synthesis," RSC Advances, vol. 2, no. 11, pp. 4547-4592, 2012.

[33] K. Tanaka, Solvent-Free Organic Synthesis, Wiley-VCH GmbH \& Co. KGaA, Weinheim, Germany, 2003.

[34] R. S. Varma, "Solvent-free organic syntheses using supported reagents and microwave irradiation," Green Chemistry, vol. 1, no. 1 , pp. 43-55, 1999. 
[35] R. S. Varma, "Solvent-free accelerated organic syntheses using microwaves," Pure and Applied Chemistry, vol. 73, no. 1, pp. 193198, 2001.

[36] M. H. Sarvari and H. Sharghi, "Zinc oxide $(\mathrm{ZnO})$ as a new, highly efficient, and reusable catalyst for acylation of alcohols, phenols and amines under solvent free conditions," Tetrahedron, vol. 61, no. 46, pp. 10903-10907, 2005.

[37] K. Wilson and J. H. Clark, "Solid acids and their use as environmentally friendly catalysts in organic synthesis," Pure and Applied Chemistry, vol. 72, no. 7, pp. 1313-1319, 2000.

[38] A. Loupy, "Solvent-free reactions," Topics in Current Chemistry, vol. 206, pp. 153-207, 1999.

[39] R. H. Andreatta and H. Rink, "Zur problematik der peptidsynthese an tragern: beitrag eines neuen Verfahrens mit loslichen tragern," Helvetica Chimica Acta, vol. 56, no. 4, pp. 1205-1218, 1973.

[40] M. M. Shemyakin, Y. A. Ovchinnikov, A. A. Kinyushkin, and I. V. Kozhevnikova, "Synthesis of peptides in solution on a polymeric support I. Synthesis of glycylglycyl-l-leucylglycine," Tetrahedron Letters, vol. 6, no. 27, pp. 2323-2327, 1965.

[41] S. H. L. Chiu and L. Anderson, "Oligosaccharide synthesis by the thioglycoside scheme on soluble and insoluble polystyrene supports," Carbohydrate Research, vol. 50, no. 2, pp. 227-238, 1976.

[42] S. Chert and K. D. Janda, "Synthesis of prostaglandin E2 methyl ester on a soluble-polymer support for the construction of prostanoid libraries," Journal of the American Chemical Society, vol. 119, no. 37, pp. 8724-8725, 1997.

[43] H. Hayatsu and H. G. Khorana, "Studies on polynucleotides. LXXII. Deoxyribooligonucleotide synthesis on a polymer support," Journal of the American Chemical Society, vol. 89, no. 15, pp. 3880-3887, 1967.

[44] M. Narita, "Liquid phase peptide synthesis by the fragment condensation on soluble polymer support. I. Efficient coupling and relative reactivity of a peptide fragment with various coupling reagents," Bulletin of the Chemical Society of Japan, vol. 51, no. 5, pp. 1477-1480, 1978.

[45] E. Cramer, R. Helbig, H. Hettler, K. H. Scheit, and H. Seliger, "Oligonucleotid-Synthese an einem löslichen Polymeren als Träger," Angewandte Chemie, vol. 78, no. 12, pp. 640-641, 1966.

[46] R. L. Letsinger and M. J. Kornet, "Popcorn polymer as a support in multistep syntheses," Journal of the American Chemical Society, vol. 85, no. 19, pp. 3045-3046, 1963.

[47] A. Guyot, "Polymer supports with high accessibility," Pure and Applied Chemistry, vol. 60, no. 3, pp. 365-376, 1988.

[48] F. Svec and J. M. J. Frchet, "New designs of macroporous polymers and supports: from separation to biocatalysis," Science, vol. 273, no. 5272, pp. 205-211, 1996.

[49] M. Hori, D. J. Gravert, R. Wentworth, and K. D. Janda, "Investigating highly crosslinked macroporous resins for solidphase synthesis," Bioorganic \& Medicinal Chemistry Letters, vol. 8, no. 17, pp. 2363-2368, 1998.

[50] E. R. L. Malenfant and J. M. J. Frchet, "The first solid-phase synthesis of oligothiophenes," Chemical Communications, no. 23, pp. 2657-2658, 1998.

[51] G. W. Kabalka and R. M. Pagni, "Organic reactions on alumina," Tetrahedron, vol. 53, no. 24, pp. 7999-8065, 1997.

[52] B. Basu and B. Mandal, "KF/alumina: a potential heterogeneous base for organic reactions," Current Organic Chemistry, vol. 15, no. 22, pp. 3870-3893, 2011.
[53] T. Ando, S. J. Brown, J. H. Clark et al., "Alumina-supported fluoride reagents for organic synthesis: optimisation of reagent preparation and elucidation of the active species," Journal of the Chemical Society, Perkin Transactions 2, no. 8, pp. 1133-1139, 1986.

[54] T. Ando, J. H. Clark, D. G. Cork, and T. Kimura, "Surface analysis of MF-aluminas and related supported reagents by scanning electron microscopy," Bulletin of the Chemical Society of Japan, vol. 59, no. 10, pp. 3281-3282, 1986.

[55] T. Ando, J. H. Clark, D. G. Cork, T. Hanafusa, J. Ichihara, and T. Kimura, "Fluoride-alumina reagents: the active basic species," Tetrahedron Letters, vol. 28, no. 13, pp. 1421-1424, 1987.

[56] J. H. Clark, "Fluoride ion as a base in organic synthesis," Chemical Reviews, vol. 80, no. 5, pp. 429-452, 1980.

[57] A. Loupy, A. Petit, J. Hamelin, F. Texier-Boullet, P. Jacquault, and D. Mathé, "New solvent-free organic synthesis using focused microwaves," Synthesis, no. 9, pp. 1213-1234, 1998.

[58] A. Guram and S. L. Buchwald, "Palladium-catalyzed aromatic aminations with in situ generated aminostannanes," Journal of the American Chemical Society, vol. 116, no. 17, pp. 7901-7902, 1994.

[59] J. P. Wolfe, S. Wagaw, J.-F. Marcoux, and S. L. Buchwald, "Rational development of practical catalysts for aromatic carbonnitrogen bond formation," Accounts of Chemical Research, vol. 31, no. 12, pp. 805-818, 1998.

[60] J. Louie and J. F. Hartwig, "Palladium-catalyzed synthesis of arylamines from aryl halides. Mechanistic studies lead to coupling in the absence of tin reagents," Tetrahedron Letters, vol. 36, no. 21, pp. 3609-3612, 1995.

[61] J. F. Hartwig, "Approaches to catalyst discovery. New carbonheteroatom and carbon-carbon bond formation," Pure and Applied Chemistry, vol. 71, no. 8, pp. 1417-1423, 1999.

[62] D. W. Old, J. P. Wolfe, and S. L. Buchwald, "A highly active catalyst for palladium-catalyzed cross-coupling reactions: roomtemperature Suzuki couplings and amination of unactivated aryl chlorides," Journal of the American Chemical Society, vol. 120, no. 37, pp. 9722-9723, 1998.

[63] B. Basu, S. Jha, N. K. Mridha, and M. M. H. Bhuiyan, "Palladium-catalysed amination of halopyridines on a KFalumina surface," Tetrahedron Letters, vol. 43, no. 44, pp. 79677969, 2002.

[64] B. Basu, P. Das, A. K. Nanda, S. Das, and S. Sarkar, "Palladiumcatalyzed selective amination of haloaromatics on KF-alumina surface," Synlett, no. 8, pp. 1275-1278, 2005.

[65] D. A. Oare and C. H. Heathcock, "Stereochemistry of the basepromoted Michael addition reaction," in Topics in Stereochemistry, E. L. Eliel and S. H. Willen, Eds., vol. 19, p. 277, John Wiley and Sons, New York, NY, USA, 1989.

[66] J. D’Angelo, G. Revial, P. R. R. Costa, R. N. Castro, and O. A. C. Antunes, "Asymmetric Michael addition of chiral imines to phenylvinylsulfone: preparation of key chiral building blocks for the synthesis of Aspidosperma and Hunteria alkaloids," Tetrahedron Asymmetry, vol. 2, no. 3, pp. 199-202, 1991.

[67] B. List, P. Pojarliev, and H. J. Martin, "Efficient proline-catalyzed Michael additions of unmodified ketones to nitro olefins," Organic Letters, vol. 3, no. 16, pp. 2423-2425, 2001.

[68] A. Alexakis and O. Andrey, "Diamine-catalyzed asymmetric Michael additions of aldehydes and ketones to nitrostyrene," Organic Letters, vol. 4, no. 21, pp. 3611-3614, 2002.

[69] B. Basu, P. Das, and I. Hossain, "KF-alumina-mediated selective double Michael additions of aryl methyl ketones: a facile 
entry to the synthesis of functionalized pimelate esters and derivatives," Synlett, no. 12, pp. 2224-2226, 2004.

[70] D. A. Horton, G. T. Bourne, and M. L. Smythe, "The combinatorial synthesis of bicyclic privileged structures or privileged substructures," Chemical Reviews, vol. 103, no. 3, pp. 893-930, 2003.

[71] G. Bringmann, C. Gunther, M. Ochse, O. Schupp, and S. Tasler, "Biaryls in nature: a multi-facetted class of stereochemically, biosynthetically, and pharmacologically intriguing secondary metabolites," in Progress in the Chemistry of Organic Natural Products, W. Herz, H. Falk, G. W. Kirby, and R. E. Moore, Eds., vol. 82, Springer, New York, NY, USA, 2001.

[72] P. J. Hajduk, M. Bures, J. Praestgaard, and S. W. Fesik, "Privileged molecules for protein binding identified from NMR-based screening," Journal of Medicinal Chemistry, vol. 43, no. 18, pp. 3443-3447, 2000.

[73] G. W. Bemis and M. A. Murcko, "The properties of known drugs. 1. Molecular frameworks," Journal of Medicinal Chemistry, vol. 39, no. 15, pp. 2887-2893, 1996.

[74] U. Schmidt, V. Leitenberger, H. Griesser, J. Schmidt, and R. Meyer, "Total synthesis of the biphenomycins; V. Synthesis of biphenomycin A," Synthesis, no. 12, pp. 1248-1254, 1992.

[75] U. Schmidt, R. Meyer, V. Leitenberger, H. Griesser, and A. Lieberknecht, "Total synthesis of the biphenomycins; III. Synthesis of biphenomycin B," Synthesis, no. 10, pp. 1025-1030, 1992.

[76] A. Markham and K. L. Goa, "Valsartan," Drugs, vol. 54, no. 2, pp. 299-311, 1997.

[77] K. F. Croom and G. M. Keating, "Valsartan," American Journal of Cardiovascular Drugs, vol. 4, no. 6, pp. 395-404, 2004.

[78] M. Sharpe, B. Jarvis, and K. L. Goa, "Telmisartan: a review of its use in hypertension," Drugs, vol. 61, no. 10, pp. 1501-1529, 2001.

[79] S. Yusuf, "From the hope to the ontarget and the transcend studies: challenges in improving prognosis," American Journal of Cardiology, vol. 89, no. 2, pp. 18-25, 2002.

[80] M. E. Matheron and M. Porchas, "Activity of boscalid, fenhexamid, fluazinam, fludioxonil, and vinclozolin on growth of sclerotinia minor and s. sclerotiorum and development of lettuce drop," Plant Disease, vol. 88, no. 6, pp. 665-668, 2004.

[81] B. Basu, P. Das, M. M. H. Bhuiyan, and S. Jha, "Microwaveassisted Suzuki coupling on a KF-alumina surface: synthesis of polyaryls," Tetrahedron Letters, vol. 44, no. 19, pp. 3817-3820, 2003.

[82] P. Das and B. Basu, "Microwave-assisted copper promoted Narylation of amines with aryl boronic acids/salts on a KFalumina surface," Synthetic Communications, vol. 34, no. 12, pp. 2177-2184, 2004.

[83] A. Gomtsyan, E. K. Bayburt, R. G. Schmidt et al., "Novel transient receptor potential vanilloid 1 receptor antagonists for the treatment of pain; Structure-activity relationships for ureas with quinoline, isoquinoline, quinazoline, phthalazine, quinoxaliue, and cinnoline moieties," Journal of Medicinal Chemistry, vol. 48, no. 3, pp. 744-752, 2005.

[84] R. Sarges, H. R. Howard, R. G. Browne, L. A. Lebel, P. A. Seymour, and B. K. Koe, "4-amino[1,2,4]triazolo[4,3a]quinoxalines. A novel class of potent adenosine receptor antagonists and potential rapid-onset antidepressants," Journal of Medicinal Chemistry, vol. 33, no. 8, pp. 2240-2254, 1990.

[85] L. E. Seitz, W. J. Suling, and R. C. Reynolds, "Synthesis and antimycobacterial activity of pyrazine and quinoxaline derivatives," Journal of Medicinal Chemistry, vol. 45, no. 25, pp. 5604-5606, 2002.
[86] A. Jaso, B. Zarranz, I. Aldana, and A. Monge, "Synthesis of new quinoxaline-2-carboxylate 1,4-dioxide derivatives as anti-mycobacterium tuberculosis agents," Journal of Medicinal Chemistry, vol. 48, no. 6, pp. 2019-2025, 2005.

[87] W. He, M. R. Myers, B. Hanney et al., "Potent quinoxaline-based inhibitors of PDGF receptor tyrosine kinase activity-part 2: the synthesis and biological activities of RPR127963 an orally bioavailable inhibitor," Bioorganic and Medicinal Chemistry Letters, vol. 13, no. 18, pp. 3097-3100, 2003.

[88] M. M. Ali, M. M. F. Ismail, M. S. A. El-Gaby, M. A. Zahran, and Y. A. Ammar, "Synthesis and antimicrobial activities of some novel quinoxalinone derivatives," Molecules, vol. 5, no. 6, pp. 864-873, 2000.

[89] G. Saka, K. Makino, and Y. Kurasawa, "Recent progress in the quinoxaline chemistry. Synthesis and biological activity," Heterocycles, vol. 27, no. 10, pp. 2481-2515, 1988.

[90] S. Paul and B. Basu, "Synthesis of libraries of quinoxalines through eco-friendly tandem oxidation-condensation or condensation reactions," Tetrahedron Letters, vol. 52, no. 49, pp. 6597-6602, 2011

[91] A. I. Vogel, A. R. Tatchell, B. S. Furnis, A. J. Hannaford, and P. W. G. Smith, Vogel's Textbook of Practical Organic Chemistry, Longman Group, London, UK, 1989.

[92] J. Frackenpohl, P. I. Arvidsson, J. V. Schreiber, and D. Seebach, "The outstanding biological stability of $\beta$ - and $\gamma$-peptides toward proteolytic enzymes: an in vitro investigation with fifteen peptidases," ChemBioChem, vol. 2, no. 6, pp. 445-455, 2001.

[93] G. Cardillo and C. Tomasini, "Asymmetric synthesis of $ß$ amino acids and $\alpha$-substituted $\beta$-amino acids," Chemical Society Reviews, vol. 25, no. 2, pp. 117-128, 1996.

[94] K. C. Nicolaou, V.-M. Dai, and R. K. Guy, "Chemistry and biology of taxol," Angewandte Chemie-International Edition, vol. 33, no. 1, pp. 15-44, 1994.

[95] F. Texier-Boullet, R. Latouche, and J. Hamelin, "Synthesis in dry media coupled with microwave irradiation: application to the preparation of $\beta$-aminoesters and $\beta$-lactams via silyl ketene acetals and aldimines," Tetrahedron Letters, vol. 34, no. 13, pp. 2123-2126, 1993.

[96] E. J. Corey, C. P. Decicco, and R. C. Newbold, "Highly enantioselective and diastereoselective synthesis of $\beta$-amino acid esters and $\beta$-lactams from achiral esters and imines," Tetrahedron Letters, vol. 32, no. 39, pp. 5287-5290, 1991.

[97] T. N. Salzman, R. W. Ratcliffe, B. G. Christensen, and F. A. Boufford, "A stereocontrolled synthesis of (+)-thienamycin," Journal of the American Chemical Society, vol. 102, no. 19, pp. 6161-6163, 1980.

[98] J. Seyden-Penne, Chiral Auxiliaries and Ligands in Asymmetric Synthesis, John Wiley and Sons, New York, NY, USA, 1995.

[99] B. Basu, P. Das, and I. Hossain, "Synthesis of $\beta$-amino esters via aza-Michael addition of amines to alkenes promoted on silica: a useful and recyclable surface," Synlett, no. 14, pp. 2630-2632, 2004.

[100] B. C. Ranu, S. S. Dey, and A. Hajra, "Solvent-free, catalyst-free Michael-type addition of amines to electron-deficient alkenes," Arkivoc, vol. 2002, no. 7, pp. 76-81, 2002.

[101] C. Brielles, J. J. Harnett, and E. Doris, "Diethylzinc/CuIImediated alkylation of aromatic amines and related compounds," Tetrahedron Letters, vol. 42, no. 47, pp. 8301-8302, 2001. 
[102] D. H. R. Barton and E. Doris, "Alkylation of aromatic amines and related compounds using a copper(II)-aluminum(III) couple," Tetrahedron Letters, vol. 37, no. 19, pp. 3295-3298, 1996.

[103] S. Yuvaraj, V. V. Balasubramanian, and M. Palanichamy, "Nethylation of aniline with ethanol or diethyl carbonate over alkali and alkaline zeolites Y and $\beta$," Applied Catalysis A, vol. 176, no. 1, pp. 111-117, 1999.

[104] D. Y. Yoshida and Y. Tanabe, "Direct and selective Nmonoalkynylation and $\mathrm{N}$-monoalkenylation of anilines with alky(e)nyl methanesulfonates using methylmagnesium bromide as a base," Synthesis, no. 5, pp. 533-535, 1997.

[105] S. Narayanan and K. Deshpande, "A comparative aniline alkylation activity of montmorillonite and vanadia-montmorillonite with silica and vanadia-silica," Applied Catalysis A, vol. 135, no. 1, pp. 125-135, 1996.

[106] P. S. Singh, R. Bandyopadhyay, and B. S. Rao, "Aniline methylation over AEL type molecular sieves," Applied Catalysis A, vol. 136, no. 2, pp. 177-189, 1996.

[107] M. A. Aramendia, V. Borau, C. Jimenez, J. M. Marinas, and F. J. Romero, "N-alkylation of aniline with methanol over magnesium phosphates," Applied Catalysis A, vol. 183, no. 1, pp. 73-80, 1999.

[108] B. L. Su and D. Barthbomeuf, "Alkylation of aniline with methanol: change in selectivity with acido-basicity of faujasite catalysts," Applied Catalysis A, vol. 124, no. 1, pp. 73-80, 1995.

[109] I. I. Ivanova, E. B. Pomakhina, A. I. Rebrov, M. Hunger, Y. G. Kolyagin, and J. Weitkamp, "Surface species formed during aniline methylation on zeolite $\mathrm{H}-\mathrm{Y}$ investigated by in situ MAS NMR spectroscopy," Journal of Catalysis, vol. 203, no. 2, pp. 375381, 2001.

[110] K. Nishamol, K. S. Rahna, and S. Sugunan, "Selective alkylation of aniline to $\mathrm{N}$-methyl aniline using chromium manganese ferrospinels," Journal of Molecular Catalysis A, vol. 209, no. 1-2, pp. 89-96, 2004.

[111] K. Okano, H. Tokuyamaand, and T. Fukuyama, "Synthesis of secondary arylamines through copper-mediated intermolecular aryl amination," Organic Letters, vol. 5, no. 26, pp. 49874990, 2003.

[112] A.-N. Ko, C.-L. Yang, W. Zhu, and H. Lin, "Selective Nalkylation of aniline with methanol over $\gamma$-alumina," Applied Catalysis A, vol. 134, no. 1, pp. 53-66, 1996.

[113] M. Selva, P. Tundo, and A. Perosa, "Reaction of primary aromatic amines with alkyl carbonates over $\mathrm{NaY}$ faujasite: a convenient and selective access to mono-N-alkyl anilines," Journal of Organic Chemistry, vol. 66, no. 3, pp. 677-680, 2001.

[114] B. Basu, S. Paul, and A. K. Nanda, "Highly selective N-alkylation of amines promoted on silica: an efficient and recyclable surface," Green Chemistry, vol. 11, no. 8, pp. 1115-1120, 2009.

[115] T. W. Greene and P. G. M. Wuts, Protective Groups in Organic Synthesis, John Wiley and Sons, New York, NY, USA, 1999.

[116] B. J. R. Hanson, Protective Groups in Organic Synthesis, Blackwell Science Inc., Malden, Mass, USA, 1999.

[117] P. A. Hemsley, "Reviews on protein acylation and microdomains in membrane function. Protein S-acylation in plants (review)," Molecular Membrane Biology, vol. 26, pp. 114-125, 2009.

[118] M. F. G. Schmidt, "Fatty acylation of proteins," Biochimica et Biophysica Acta, vol. 988, no. 3, pp. 411-426, 1989.

[119] R. Leventis, G. Juel, J. K. Knudsen, and J. R. Silvius, "AcylCoA binding proteins inhibit the nonenzymic S-acylation of cysteinyl-containing peptide sequences by long-chain acylCoAs," Biochemistry, vol. 36, no. 18, pp. 5546-5553, 1997.
[120] M. Veit, E. Ponimaskin, and M. F. G. Schmidt, "Analysis of sacylation of proteins," Methods in Molecular Biology, vol. 446, pp. 163-182, 2008.

[121] H. Schroeder, R. Leventis, S. Rex et al., "S-acylation and plasma membrane targeting of the farnesylated carboxyl- terminal peptide of N-ras in mammalian fibroblasts," Biochemistry, vol. 36, no. 42, pp. 13102-13109, 1997.

[122] F. Eisele, D. J. Owen, and H. Waldman, "Peptide conjugates as tools for the study of biological signal transduction," Bioorganic \& Medicinal Chemistry, vol. 7, no. 2, pp. 193-224, 1999.

[123] B. Basu, S. Paul, and A. K. Nanda, "Silica-promoted facile synthesis of thioesters and thioethers: a highly efficient, reusable and environmentally safe solid support," Green Chemistry, vol. 12, no. 5, pp. 767-771, 2010.

[124] K.-J. Soderlind, B. Gorodetsky, A. K. Singh, N. R. Bachur, G. G. Miller, and J. W. Lown, "Bis-benzimidazole anticancer agents: targeting human tumour helicases," Anti-Cancer Drug Design, vol. 14, no. 1, pp. 19-36, 1999.

[125] Y. Bai, J. Lu, Z. Shi, and B. Yang, "Synthesis of 2,15-hexadecanedione as a precursor of muscone," Synlett, no. 4, pp. 544546, 2001.

[126] E. Bouwman, W. L. Driessen, and J. Reedjik, "Model systems for type I copper proteins: structures of copper coordination compounds with thioether and azole-containing ligands," Coordination Chemistry Reviews, vol. 104, no. 1, pp. 143-172, 1990.

[127] M. A. Pujar, T. D. Bharamgoudar, and D. N. Sathyanarayana, "Cobalt(II), nickel(II) and copper(II) complexes of bidentate bibenzimidazoles," Transition Metal Chemistry, vol. 13, no. 6, pp. 423-425, 1988.

[128] D. Yang, D. Fokas, J. Li, L. Yu, and C. M. Baldino, "A versatile method for the synthesis of benzimidazoles from o-nitroanilines and aldehydes in one step via a reductive cyclization," Synthesis, no. 1, pp. 47-56, 2005.

[129] R. Trivedi, S. K. De, and R. A. Gibbs, "A convenient one-pot synthesis of 2-substituted benzimidazoles," Journal of Molecular Catalysis A, vol. 245, no. 1-2, pp. 8-11, 2006.

[130] K. Bahrami, M. M. Khodaei, and I. Kavianinia, "A simple and efficient one-pot synthesis of 2-substituted benzimidazoles," Synthesis, no. 4, pp. 547-550, 2007.

[131] K. Bahrami, M. Mehdi Khodaei, and F. Naali, "Mild and highly efficient method for the synthesis of 2-arylbenzimidazoles and 2-arylbenzothiazoles," Journal of Organic Chemistry, vol. 73, no. 17, pp. 6835-6837, 2008.

[132] H. Sharghi, M. Aberi, and M. M. Doroodmand, "Reusable cobalt(III)-salen complex supported on activated carbon as an efficient heterogeneous catalyst for synthesis of 2arylbenzimidazole derivatives," Advanced Synthesis and Catalysis, vol. 350, no. 14-15, pp. 2380-2390, 2008.

[133] Y. X. Chen, L. F. Qian, W. Zhang, and B. Han, "Efficient aerobic oxidative synthesis of 2-substituted benzoxazoles, benzothiazoles, and benzimidazoles catalyzed by 4-methoxy-TEMPO," Angewandte Chemie -International Edition, vol. 47, no. 48, pp. 9330-9333, 2008.

[134] D. Saha, A. Saha, and B. C. Ranu, "Remarkable influence of substituent in ionic liquid in control of reaction: simple, efficient and hazardous organic solvent free procedure for the synthesis of 2-aryl benzimidazoles promoted by ionic liquid, [pmim]BF4," Green Chemistry, vol. 11, no. 5, pp. 733-737, 2009.

[135] C. R. C. Luisa, E. Fernandes, and M. M. B. Marques, "Developments towards regioselective synthesis of 1,2-disubstituted benzimidazoles," Chemistry - A European Journal, vol. 17, no. 45, pp. 12544-12555, 2011. 
[136] S. das Sharma and D. Konwar, "Practical, ecofriendly, and chemoselective method for the synthesis of 2-aryl-1-arylmethyl$1 \mathrm{H}$-benzimidazoles using amberlite IR-120 as a reusable heterogeneous catalyst in aqueous media," Synthetic Communications, vol. 39, no. 6, pp. 980-991, 2009.

[137] K. Bahrami, M. M. Khodaei, and A. Nejati, "Synthesis of 1,2-disubstituted benzimidazoles, 2-substituted benzimidazoles and 2-substituted benzothiazoles in SDS micelles," Green Chemistry, vol. 12, no. 7, pp. 1237-1241, 2010.

[138] J.-P. Wan, S.-F. Gan, J.-M. Wu, and Y. Pan, "Water mediated chemoselective synthesis of 1,2-disubstituted benzimidazoles using o-phenylenediamine and the extended synthesis of quinoxalines," Green Chemistry, vol. 11, no. 10, pp. 1633-1637, 2009.

[139] S. Das Sharma and D. Konwar, Synthetic Communications, vol. 39, no. 6, pp. 980-991, 2009.

[140] S. Santra, A. Majee, and A. Hajra, "Nano indium oxide: an efficient catalyst for the synthesis of 1,2-disubstituted benzimidazoles in aqueous media," Tetrahedron Letters, vol. 53, no. 15, pp. 1974-1977, 2012.

[141] S. Paul and B. Basu, "Highly selective synthesis of libraries of 1,2disubstituted benzimidazoles using silica gel soaked with ferric sulfate," Tetrahedron Letters, vol. 53, no. 32, pp. 4130-4133, 2012.

[142] P. Morys and T. Schlieper, "Synthesis and catalytic activity of silica supported iron(III)," Journal of Molecular Catalysis A, vol. 95, no. 1, pp. 27-33, 1995.

[143] J. Xu and C. H. Bartholomew, "Temperature-programmed hydrogenation (TPH) and in situ Mössbauer spectroscopy studies of carbonaceous species on silica-supported iron FischerTropsch catalysts," The Journal of Physical Chemistry B, vol. 109, no. 6, pp. 2392-2403, 2005.

[144] D. D. E. Koyuncu and S. Yasyerli, "Selectivity and stability enhancement of iron oxide catalyst by Ceria Incorporation for selective oxidation of $\mathrm{H}_{2} \mathrm{~S}$ to sulfur," Industrial \& Engineering Chemistry Research, vol. 48, no. 11, pp. 5223-5229, 2009.

[145] D. J. Kim, B. C. Dunn, F. Huggins et al., "SBA-15-supported iron catalysts for Fischer-Tropsch production of diesel fuel," Energy and Fuels, vol. 20, no. 6, pp. 2608-2611, 2006.

[146] G. A. Bukhtiyarova, V. I. Bukhtiyarov, N. S. Sakaeva, V. V. Kaichev, and B. P. Zolotovskii, "XPS study of the silicasupported Fe-containing catalysts for deep or partial $\mathrm{H}_{2} \mathrm{~S}$ oxidation," Journal of Molecular Catalysis A, vol. 158, no. 1, pp. 251-255, 2000.

[147] Z. Ma, Y. Ke, H. Wang et al., "Ethylene polymerization with a silica-supported iron-based diimine catalyst," Journal of Applied Polymer Science, vol. 88, no. 2, pp. 466-469, 2003.

[148] A.-T. Pham, C. Lee, F. M. Doyle, and D. L. Sedlak, "A silicasupported iron oxide catalyst capable of activating hydrogen peroxide at neutral $\mathrm{pH}$ values," Environmental Science \& Technology, vol. 43, no. 23, pp. 8930-8935, 2009.

[149] S. Moreton, "Silica gel impregnated with iron(III) salts: a safe humidity indicator," Material Research Innovations, vol. 5, no. 5, pp. 226-229, 2002.

[150] K. Bahrami, M. M. Khodaei, and A. Nejati, "Synthesis of 1,2-disubstituted benzimidazoles, 2-substituted benzimidazoles and 2-substituted benzothiazoles in SDS micelles," Green Chemistry, vol. 12, no. 7, pp. 1237-1241, 2010.

[151] M. Amirnasr, K. J. Schenk, A. Gorji, and R. Vafazadeh, "Synthesis and spectroscopic characterization of [CoIII(salophen $\left.(\text { amine })_{2}\right] \mathrm{ClO}_{4}$ (amine $=$ morpholine, pyrrolidine, and piperidine) complexes. The crystal structures of
[CoIII(salophen)(morpholine) $\left.{ }_{2}\right] \mathrm{ClO}_{4}$ and $[\mathrm{CoIII}($ salophen) (pyrrolidine)2 $\mathrm{ClO}_{4}$," Polyhedron, vol. 20, no. 7-8, pp. 695-702, 2001.

[152] K. W. Pepper, H. M. Paisley, and M. A. Young, "Properties of ion-exchange resins in relation to their structure-part VI: anion-exchange resins derived from styrene-divinyl-benzene copolymers," Journal of the Chemical Society, pp. 4097-4105, 1953.

[153] R. V. Law, D. C. Sherrington, C. E. Snape, I. Ando, and H. Kurosu, "Solid-state13C MAS NMR studies of hyper-crosslinked polystyrene resins," Macromolecules, vol. 29, no. 19, pp. 6284-6293, 1996.

[154] S. Pickup, F. D. Blum, W. T. Ford, and M. Periyasamy, “Transport of small molecules in swollen polymer beads," Journal of the American Chemical Society, vol. 108, no. 14, pp. 3987-3990, 1986.

[155] T. Balakrishnan and W. T. Ford, "Particle size control in suspension copolymerization of styrene, chloromethylstyrene, and divinylbenzene," Journal of Applied Polymer Science, vol. 27, no. 1, pp. 133-138, 1982.

[156] R. Quarrell, T. D. Claridge, G. W. Weaver, and G. Lowe, "Structure and properties of TentaGel resin beads: implications for combinatorial library chemistry," Molecular Diversity, vol. 4, no. 4, pp. 223-232, 1996.

[157] C. M. G. Judkins, K. A. Knights, B. F. G. Johnson, Y. R. de Miguel, R. Raja, and J. M. Thomas, "Immobilisation of ruthenium cluster catalysts via novel derivatisations of ArgoGel resins," Chemical Communications, no. 24, pp. 2624-2625, 2001.

[158] D. Astruc, Nanoparticles and Catalysis, Wiley-VCH, Weinheim, Germany, 2008.

[159] S. Kobayashi and R. Akiyama, "Renaissance of immobilized catalysts. New types of polymer-supported catalysts, 'microencapsulated catalysts', which enable environmentally benign and powerful high-throughput organic synthesis," Chemical Communications, no. 4, pp. 449-460, 2003.

[160] S. Kobayashi and R. Akiyama, "New methods for highthroughput synthesis," Pure and Applied Chemistry, vol. 73, no. 7, pp. 1103-1111, 2001.

[161] P. Rylander, Catalytic Hydrogenation in Organic Synthesis, Academic Press, New York, NY, USA, 1979.

[162] N. Ono, The Nitro Group in Organic Synthesis, Wiley-VCH, New York, NY, USA, 2001.

[163] E. A. Braude and R. P. Linstead, "Hydrogen transfer-part I: introductory survey," Journal of the Chemical Society, pp. 35443547, 1954.

[164] G. Brieger and T. J. Nestrick, "Catalytic transfer hydrogenation," Chemical Reviews, vol. 74, no. 5, pp. 567-580, 1974.

[165] R. A. W. Johnstone, A. H. Wilby, and I. D. Entwistle, "Heterogeneous catalytic transfer hydrogenation and its relation to other methods for reduction of organic compounds," Chemical Reviews, vol. 85, no. 2, pp. 129-170, 1985.

[166] M. Takasaki, Y. Motoyama, K. Higashi, S.-H. Yoon, I. Mochida, and H. Nagashima, "Chemoselective hydrogenation of nitroarenes with carbon nanofiber-supported platinum and palladium nanopraticles," Organic Letters, vol. 10, no. 8, pp. 1601-1604, 2008.

[167] S. K. Mohapatra, S. U. Sonavane, R. V. Jayaram, and P. Selvam, "Heterogeneous catalytic transfer hydrogenation of aromatic nitro and carbonyl compounds over cobalt(II) substituted hexagonal mesoporous aluminophosphate molecular sieves," Tetrahedron Letters, vol. 43, no. 47, pp. 8527-8529, 2002. 
[168] R. V. Jagadeesh, G. Wienhöfer, F. A. Westerhaus et al., "Efficient and highly selective iron-catalyzed reduction of nitroarenes," Chemical Communications, vol. 47, no. 39, pp. 10972-10974, 2011.

[169] A. Saha and B. C. Ranu, "Highly chemoselective reduction of aromatic nitro compounds by copper nanoparticles/ammonium formate," The Journal of Organic Chemistry, vol. 73, no. 17, pp. 6867-6870, 2008.

[170] R. J. Rahaim Jr. and R. E. Maleczka Jr., "Pd-catalyzed silicon hydride reductions of aromatic and aliphatic nitro groups," Organic Letters, vol. 7, no. 22, pp. 5087-5090, 2005.

[171] K. Nomura, "Efficient selective reduction of aromatic nitro compounds by ruthenium catalysis under $\mathrm{CO} / \mathrm{H}_{2} \mathrm{O}$ conditions," Journal of Molecular Catalysis A, vol. 95, no. 3, pp. 203-210, 1995.

[172] L. He, L.-C. Wang, H. Sun et al., "Efficient and selective roomtemperature gold-catalyzed reduction of nitro compounds with $\mathrm{CO}$ and $\mathrm{H}_{2} \mathrm{O}$ as the hydrogen source," Angewandte ChemieInternational Edition, vol. 48, no. 50, pp. 9538-9541, 2009.

[173] R. V. Niquirilo, E. Teixeira-Neto, G. S. Buzzo, and H. B. Suffredini, "Formic acid oxidation at Pd, Pt and PbOx-based catalysts and calculation of their approximate electrochemical active areas," International Journal of Electrochemical Science, vol. 5, no. 3, pp. 344-354, 2010.

[174] B. Basu, M. M. H. Bhuiyan, P. Das, and I. Hossain, "Catalytic transfer reduction of conjugated alkenes and an imine using polymer-supported formates," Tetrahedron Letters, vol. 44, no. 50, pp. 8931-8934, 2003.

[175] N. A. Cortese and R. F. Heck, "Palladium catalyzed reductions of halo- and nitroaromatic compounds with triethylammonium formate," The Journal of Organic Chemistry, vol. 42, no. 22, pp. 3491-3494, 1977.

[176] H. Weiner, J. Blum, and Y. Sasson, "Studies on the mechanism of transfer hydrogenation of nitro arenes by formate salts catalyzed by palladium/carbon," The Journal of Organic Chemistry, vol. 56, no. 14, pp. 4481-4486, 1991.

[177] D. C. Gowda, A. S. P. Gowda, A. R. Baba, and S. Gowda, "Nickelcatalyzed formic acid reductions. A selective method for the reduction of nitro compounds," Synthetic Communications, vol. 30, no. 16, pp. 2889-2895, 2000.

[178] K. Hanaya, T. Muramatsu, H. Kudo, and Y. L. Chow, "Reduction of aromatic nitro-compounds to amines with sodium borohydride-copper(II) acetylacetonate," Journal of the Chemical Society, Perkin Transactions 1, pp. 2409-2410, 1979.

[179] N. Pradhan, A. Pal, and T. Pal, "Silver nanoparticle catalyzed reduction of aromatic nitro compounds," Colloids and Surfaces A, vol. 196, no. 2-3, pp. 247-257, 2002.

[180] B. Basu, P. Das, and S. Das, "Transfer hydrogenation using recyclable polymer-supported formate (PSF): efficient and chemoselective reduction of nitroarenes," Molecular Diversity, vol. 9, no. 4, pp. 259-262, 2005.

[181] P. Selvam, S. K. Mohapatra, S. U. Sonavane, and R. V. Jayaram, "Chemo- and regioselective reduction of nitroarenes, carbonyls and azo dyes over nickel-incorporated hexagonal mesoporous aluminophosphate molecular sieves," Tetrahedron Letters, vol. 45, no. 9, pp. 2003-2007, 2004.

[182] S. K. Mohapatra, S. U. Sonavane, R. V. Jayaram, and P. Selvam, "Reductive cleavage of azo dyes and reduction of nitroarenes over trivalent iron incorporated hexagonal mesoporous aluminophosphate molecular sieves," Applied Catalysis B, vol. 46, no. 1, pp. 155-163, 2003.

[183] S. K. Mohapatra, S. U. Sonavane, R. V. Jayaram, and P. Selvam, "Heterogeneous catalytic transfer hydrogenation of aromatic nitro and carbonyl compounds over cobalt(II) substituted hexagonal mesoporous aluminophosphate molecular sieves," Tetrahedron Letters, vol. 43, no. 47, pp. 8527-8529, 2002.

[184] S. K. Mohapatra, S. U. Sonavane, R. V. Jayaram, and P. Selvam, "Regio- and chemoselective catalytic transfer hydrogenation of aromatic nitro and carbonyl as well as reductive cleavage of azo compounds over novel mesoporous NiMCM-41 molecular sieves," Organic Letters, vol. 4, no. 24, pp. 4297-4300, 2002.

[185] A. S. Kulkarni and R. V. Jayaram, "Liquid phase catalytic transfer hydrogenation of aromatic nitro compounds on perovskites prepared by microwave irradiation," Applied Catalysis A, vol. 252, no. 2, pp. 225-230, 2003.

[186] A. S. Kulkarni and R. V. Jayaram, "Liquid phase catalytic transfer hydrogenation of aromatic nitro compounds on $\mathrm{La}_{1-x} \mathrm{Sr}_{x} \mathrm{FeO}_{3}$ perovskites prepared by microwave irradiation," Journal of Molecular Catalysis A, vol. 223, pp. 107-110, 2004.

[187] B. Basu, B. Mandal, S. Das, P. Das, and A. K. Nanda, "Chemoselective reduction of aldehydes by ruthenium trichloride and resin-bound formates," The Beilstein Journal of Organic Chemistry, vol. 4, no. 53, 2008.

[188] B. Basu, S. Das, P. Das, and A. K. Nanda, "Co-immobilized formate anion and palladium on a polymer surface: a novel heterogeneous combination for transfer hydrogenation," Tetrahedron Letters, vol. 46, no. 49, pp. 8591-8593, 2005.

[189] E.-I. Negishi, Organopalladium Chemistry for Organic Synthesis, Wiley-InterScience, New York, NY, USA, 2002.

[190] A. D. Meijere and F. Diederich, Metal-Catalyzed Cross-Coupling Reactions, Wiley-VCH, Weinheim, Germany, 2004.

[191] C. C. Mauger and G. A. Mignani, "Synthetic applications of Buchwald's phosphines in palladium-catalyzed aromatic-bondforming reactions," Aldrichimica Acta, vol. 39, no. 1, pp. 17-24, 2006.

[192] W. A. Herrmann, K. Öfele, D. V. Preysing, and S. K. Schneider, "Phospha-palladacycles and N-heterocyclic carbene palladium complexes: efficient catalysts for CC-coupling reactions," Journal of Organometallic Chemistry, vol. 687, no. 2, pp. 229-248, 2003.

[193] L. Yin and J. Liebscher, "Carbon-carbon coupling reactions catalyzed by heterogeneous palladium catalysts," Chemical Reviews, vol. 107, no. 1, pp. 133-173, 2007.

[194] K. Sonogashira, Y. Tohda, and N. Hagihara, "A convenient synthesis of acetylenes: catalytic substitutions of acetylenic hydrogen with bromoalkenes, iodoarenes and bromopyridines," Tetrahedron Letters, vol. 16, no. 50, pp. 4467-4470, 1975.

[195] K. Sonogashira, "Coupling reactions between sp2 and sp carbon centers," in Comprehensive Organic Synthesis, B. M. Trost, Ed., vol. 3, pp. 521-549, Pergamon Press, Oxford, UK, 1999.

[196] C. J. S. Wu, M. D. Watson, L. Zhang, Z. H. Wang, and K. Mullen, "Hexakis(4-iodophenyl)-peri-hexabenzocoronene-a versatile building block for highly ordered discotic liquid crystalline materials," Journal of the American Chemical Society, vol. 126, no. 1, pp. 177-186, 2004.

[197] G. Hennrich and A. M. Echavarren, "New persubstituted 1,3,5trisethynyl benzenes via Sonogashira coupling," Tetrahedron Letters, vol. 45, no. 6, pp. 1147-1149, 2004.

[198] J. N. Wilson, M. Josowicz, Y. Q. Wang, and U. H. F. Bunz, "Cruciform $\pi$-systems: hybrid phenylene-ethynylene/phenylenevinylene oligomers," Chemical Communications, no. 24, pp. 2962-2963, 2003.

[199] C. C. Li, Z. X. Xie, Y. D. Zhang, J. H. Chen, and Z. Yang, "Total synthesis of wedelolactone," The Journal of Organic Chemistry, vol. 68, no. 22, pp. 8500-8504, 2003. 
[200] K. Y. Tsang, M. A. Brimble, and J. B. Bremner, "Use of a sonogashira-acetylide coupling strategy for the synthesis of the aromatic spiroketal skeleton of $\gamma$-rubromycin," Organic Letters, vol. 5, no. 23, pp. 4425-4427, 2003.

[201] I. Paterson, R. D. M. Davies, A. L. Heimann, R. Maquez, and A. Meyer, "Stereocontrolled total synthesis of (-)-callipeltoside A," Organic Letters, vol. 5, no. 23, pp. 4477-4480, 2003.

[202] J. W. Lane and R. L. Halcomb, "A new method for the stereoselective synthesis of $\alpha$-substituted serine amino acid analogues," Organic Letters, vol. 5, no. 22, pp. 4017-4020, 2003.

[203] T. M. Hansen, M. M. Engler, and C. J. Forsyth, "Total synthesis of a biotinylated derivative of phorboxazole A via sonogashira coupling," Bioorganic \& Medicinal Chemistry Letters, vol. 13, no. 13, pp. 2127-2130, 2003.

[204] N. Ohyaba, T. Nishkawa, and M. Isobe, "First asymmetric total synthesis of tetrodotoxin," Journal of the American Chemical Society, vol. 125, no. 29, pp. 8798-8805, 2003.

[205] J. A. Marshall and G. M. Schaaf, "Total synthesis and structure confirmation of leptofuranin D," Journal of Organic Chemistry, vol. 68 , no. 19, pp. 7428-7432, 2003.

[206] S. Lopez, F. Fernandeztrillo, L. Castedo, and C. Saa, "Synthesis of callyberynes A and B, polyacetylenic hydrocarbons from marine sponges," Organic Letters, vol. 5, no. 20, pp. 3275-3728, 2003.

[207] D. W. C. MacMillan, "The advent and development of organocatalysis," Nature, vol. 455, no. 7211, pp. 304-308, 2008.

[208] S. Kobayashi and K. Manabe, "Development of novel Lewis acid catalysts for selective organic reactions in aqueous media," Accounts of Chemical Research, vol. 35, no. 4, pp. 209-217, 2002.

[209] H. C. Kolb, M. G. Finn, and K. B. Sharpless, "Click chemistry: diverse chemical function from a few good reactions," Angewandte Chemie - International Edition, vol. 40, no. 11, pp. 20042021, 2001.

[210] S. R. Chemler, D. Trauner, and S. J. Danishefsky, "The b-alkyl Suzuki-Miyaura cross-coupling reaction: development, mechanistic study, and applications in natural product synthesis," Angewandte Chemie-International Edition, vol. 40, no. 24, pp. 4544-4568, 2001.

[211] N. Miyaura, "Synthesis of biaryls via the cross-coupling reaction of arylboronic acids," Advances in Metal-Organic Chemistry, vol. 6, pp. 187-243, 1998.

[212] L. F. Tietze, G. Kettschau, U. Heuschert, and G. Nordman, "Highly efficient synthesis of linear pyrrole oligomers by twofold Heck reactions," Chemistry - A European Journal, vol. 7, no. 2, pp. 368-373, 2001.

[213] S. Kotha, K. Lahiri, and D. Kashinath, "Recent applications of the Suzuki-Miyaura cross-coupling reaction in organic synthesis," Tetrahedron, vol. 58, no. 48, pp. 9633-9695, 2002.

[214] D. Alberico, M. E. Scott, and M. Lautens, "Aryl-aryl bond formation by transition-metal-catalyzed direct arylation," Chemical Reviews, vol. 107, no. 1, pp. 174-238, 2007.

[215] I. P. Beletskaya and A. V. Cheprakov, "Heck reaction as a sharpening stone of palladium catalysis," Chemical Reviews, vol. 100, no. 8, pp. 3009-3066, 2000.

[216] K. C. Nicolaou, H. Li, C. N. C. Boddy et al., "Total synthesis of vancomycin-part 1: design and development of methodology," Chemistry -A European Journal, vol. 5, no. 9, pp. 2584-2601, 1999.

[217] K. Kamikawa, T. Watanabe, A. Daimon, and M. Uemura, "Stereoselective synthesis of axially chiral natural products, (-)-steganone and $\mathrm{O}, \mathrm{O}^{\prime}$-dimethylkorupensamine $\mathrm{A}$, utilizing planar chiral (arene)chromium complexes," Tetrahedron, vol. 56, no. 15 , pp. 2325-2337, 2000.

[218] A. Haberli and C. J. Leumann, "Synthesis of pyrrolidine Cnucleosides via heck reaction," Organic Letters, vol. 3, no. 3, pp. 489-492, 2001.

[219] http://www.nobelprize.org/.

[220] C. Ramarao, S. V. Ley, S. C. Smith, I. M. Shirley, and N. D. Almerda, "Encapsulation of palladium in polyurea microcapsules," Chemical Communications, no. 10, pp. 1132-1133, 2002.

[221] J. Q. Yu, H. C. Wu, C. Ramarao, J. B. Spencer, and S. V. Ley, "Transfer hydrogenation using recyclable polyureaencapsulated palladium: efficient and chemoselective reduction of aryl ketones," Chemical Communications, no. 6, pp. 678-679, 2003.

[222] S. V. Ley, C. Mitchell, D. Pears, C. Ramarao, J.-Q. Yu, and W. Zhou, "Recyclable polyurea-microencapsulated $\mathrm{Pd}(0)$ nanoparticles: an efficient catalyst for hydrogenolysis of epoxides," Organic Letters, vol. 5, no. 24, pp. 4665-4668, 2003.

[223] V. Chechik and R. M. Crooks, "Dendrimer-encapsulated Pd nanoparticles as fluorous phase-soluble catalysts," Journal of the American Chemical Society, vol. 122, no. 6, pp. 1243-1244, 2000.

[224] S. Kobayashi and S. Nagayama, "A microencapsulated Lewis acid: a new type of polymer-supported Lewis acid catalyst of wide utility in organic synthesis," Journal of the American Chemical Society, vol. 120, no. 12, pp. 2985-2986, 1998.

[225] S. Kobayashi, M. Endo, and S. Nagayama, "Catalytic asymmetric dihydroxylation of olefins using a recoverable and reusable polymer-supported osmium catalyst," Journal of the American Chemical Society, vol. 121, no. 48, pp. 11229-11230, 1999.

[226] R. Akiyama and S. Kobayashi, "Microencapsulated palladium catalysts: allylic substitution and Suzuki coupling using a recoverable and reusable polymer-supported palladium catalyst," Angewandte Chemie-International Edition, vol. 40, no. 18, pp. 3469-3471, 2001.

[227] R. Akiyama and S. Kobayashi, "A novel polymer-supported arene-ruthenium complex for ring-closing olefin metathesis," Angewandte Chemie-International Edition, vol. 41, no. 14, pp. 2602-2604, 2002.

[228] R. Akiyama and S. Kobayashi, "The polymer incarcerated method for the preparation of highly active heterogeneous palladium catalysts," Journal of the American Chemical Society, vol. 125, no. 12, pp. 3412-3413, 2003.

[229] K. Okamota, R. Akiyama, and S. Kobayashi, "Recoverable, reusable, highly active, and sulfur-tolerant polymer incarcerated palladium for hydrogenation," The Journal of Organic Chemistry, vol. 69, pp. 2871-2873, 2004.

[230] K. Okamota, R. Akiyama, and S. Kobayashi, "Suzuki-Miyaura coupling catalyzed by polymer-incarcerated palladium, a highly active, recoverable, and reusable Pd catalyst," Organic Letters, vol. 6, no. 12, pp. 1987-1990, 2004.

[231] L. K. Okamota, R. Akiyama, H. Yoshida, T. Yoshida, and S. Kobayashi, "Formation of nanoarchitectures including subnanometer palladium clusters and their use as highly active catalysts," Journal of the American Chemical Society, vol. 127, no. 7, pp. 2125-2135, 2005.

[232] H. Hagio, M. Sugiura, and S. Kobayashi, "Practical preparation method of polymer-incarcerated (PI) palladium catalysts using Pd(II) salts," Organic Letters, vol. 8, no. 3, pp. 375-378, 2006.

[233] L. Strimbu, J. Liu, and A. E. Kaifer, "Cyelodextrin-capped palladium nanoparticles as catalysts for the Suzuki reaction," Langmuir, vol. 19, no. 2, pp. 483-485, 2003. 
[234] E. H. Rahim, F. S. Kamounah, J. Frederiksen, and J. B. Christensen, "Heck reactions catalyzed by PAMAM-dendrimer encapsulated $\operatorname{Pd}(0)$ nanoparticles," Nano Letters, vol. 1, no. 9, pp. 499-501, 2001.

[235] M. Pittelkow, K. Moth-Poulsen, U. Boas, and J. B. Christensen, "Poly(amidoamine)-dendrimer-stabilized $\operatorname{Pd}(0)$ nanoparticles as a catalyst for the Suzuki reaction," Langmuir, vol. 19, no. 18, pp. 7682-7684, 2003.

[236] J. C. Garcia-Martinez, R. Lezutekong, and R. M. Crooks, "Dendrimer-encapsulated Pd nanoparticles as aqueous, roomtemperature catalysts for the Stille reaction," Journal of the American Chemical Society, vol. 127, no. 14, pp. 5097-5103, 2005.

[237] D. Basu, S. Das, P. Das, B. Mandal, D. Banerjee, and F. Almqvist, "Palladium supported on a polyionic resin as an efficient, ligand-free, and recyclable catalyst for Heck, Suzuki-Miyaura, and Sonogashira reactions," Synthesis, no. 7, pp. 1137-1146, 2009.

[238] A. Kirschning, H. Monenschein, and R. Wittenberg, "The "resin-capture-release" hybrid technique: a merger between solid- and solution-phase synthesis," Chemistry-A European Journal, vol. 6, no. 24, pp. 4445-4450, 2000.

[239] http://www.cypress-international.com/image/polymerlabs/ pldmap.pdf.

[240] S. Khound and P. J. Das, "Solid phase synthesis of N-arylazoindoles," Tetrahedron, vol. 53, no. 28, pp. 9749-9754, 1997.

[241] S. Roller, H. Turk, J.-F. Stumbe, W. Rapp, and R. Haag, "Polystyrene-graft-polyglycerol resins: a new type of highloading hybrid support for organic synthesis," Journal of Combinatorial Chemistry, vol. 8, no. 3, pp. 350-354, 2006.

[242] Y. Zheng, P. D. Stevens, and Y. Gao, "Magnetic nanoparticles as an orthogonal support of polymer resins: applications to solidphase suzuki cross-coupling reactions," The Journal of Organic Chemistry, vol. 71, no. 2, pp. 537-542, 2006.

[243] T. E. Nielsen, S. Le Quement, and M. Meldal, "Solidphase synthesis of biarylalanines via Suzuki cross-coupling and intramolecular N-acyliminium Pictet-Spengler reactions," Tetrahedron Letters, vol. 46, no. 46, pp. 7959-7962, 2005.

[244] J. F. Brown, P. Krajnc, and N. R. Cameron, "PolyHIPE supports in batch and flow-through suzuki cross-coupling reactions," Industrial \& Engineering Chemistry Research, vol. 44, no. 23, pp. 8565-8572, 2005.

[245] J. T. Bork, J. W. Lee, and Y.-T. Chang, "Palladium-catalyzed cross-coupling reaction of resin-bound chlorotriazines," Tetrahedron Letters, vol. 44, no. 32, pp. 6141-6144, 2003.

[246] J. V. Wade and C. A. Krueger, "Suzuki cross-coupling of solidsupported chloropyrimidines with arylboronic acids," Journal of Combinatorial Chemistry, vol. 5, no. 3, pp. 267-272, 2003.

[247] A. Hebel and R. Haag, "Polyglycerol as a high-loading support for boronic acids with application in solution-phase Suzuki cross-couplings," Journal of Organic Chemistry, vol. 67, no. 26, pp. 9452-9455, 2002.

[248] G. Wulff, H. Schmidt, H. Witt, and R. Zentel, "Cooperativity and transfer of chirality in liquid-crystalline polymers," Angewandte Chemie-International Edition, vol. 33, no. 2, pp. 188-191, 1994.

[249] J. W. Guiles, S. G. Johnson, and W. V. Murray, "Solid-phase Suzuki coupling for C-C bond formation," Journal of Organic Chemistry, vol. 61, no. 15, pp. 5169-5171, 1996.

[250] S. R. Piettre and S. Baltzer, "A new approach to the solid-phase Suzuki coupling reaction," Tetrahedron Letters, vol. 38, no. 7, pp. 1197-1200, 1997.

[251] R. J. Kell, P. Hodge, M. Nisar, and R. T. Williams, "Facile attachment of functional moieties to crosslinked polystyrene beads via robust linkages: Suzuki reactions using polymersupported boronic acids," Journal of the Chemical Society. Perkin Transactions 1, no. 24, pp. 3403-3408, 2001.

[252] Y. Han, S. D. Walker, and R. N. Young, "Silicon directed ipso-substitution of polymer bound arylsilanes: preparation of biaryls via the Suzuki cross-coupling reaction," Tetrahedron Letters, vol. 37, no. 16, pp. 2703-2706, 1996.

[253] V. Lobrégat, G. Alcaraz, H. Bienayme, and M. Vaultier, "Application of the 'resin-capture-release' methodology to macrocyclisation via intramolecular Suzuki-Miyaura coupling," Chemical Communications, no. 9, p. 817, 2001.

[254] M. J. Farrall and J. M. J. Fréchet, "Bromination and lithiation: two important steps in the functionalization of polystyrene resins," The Journal of Organic Chemistry, vol. 41, no. 24, pp. 3877-3882, 1976.

[255] R. Frenette and R. W. Friesen, "Biaryl synthesis via suzuki coupling on a solid support," Tetrahedron Letters, vol. 35, no. 49, pp. 9177-9180, 1994.

[256] B. Basu, S. Das, S. Kundu, and B. Mandal, "Polyionic heterogeneous phenylating agent for base-free Suzuki-Miyaura coupling reaction," Synlett, no. 2, pp. 255-259, 2008.

[257] D. C. Jocelyn, Biochemistry of the Thiol Group, Academic Press, New York, NY, USA, 1992.

[258] M. Bodzansky, Principles of Peptide Synthesis, chapter 4, Springer, Berlin, Germany, 1984.

[259] G. Capozzi and G. Modena, "Oxidation of thiol," in The Chemistry of the Thiol Group, Part II, S. Patai, Ed., p. 785, John Wiley and Sons, New York, NY, USA, 1975.

[260] K. Inaba, "Disulfide bond formation system in Escherichia coli," Journal of Biochemistry, vol. 146, no. 5, pp. 591-597, 2009.

[261] W. J. Wedemeyer, E. Welker, M. Narayan, and H. A. Scheraga, "Disulfide bonds and protein folding," Biochemistry, vol. 39, no. 15, pp. 4207-4216, 2000.

[262] K. Ramadas and N. Srinivasan, "Sodium chlorite-yet another oxidant for thiols to disulphides," Synthetic Communications, vol. 25, no. 2, pp. 227-234, 1995.

[263] H. L. Fisher, "Elastomers," Industrial \& Engineering Chemistry, vol. 42, no. 10, pp. 1978-1982, 1950.

[264] D. Sengupta and B. Basu, "An efficient metal-free synthesis of organic disulfides from thiocyanates using poly-ionic resin hydroxide in aqueous medium," Tetrahedron Letters, vol. 54, no. 18, pp. 2277-2281, 2013. 

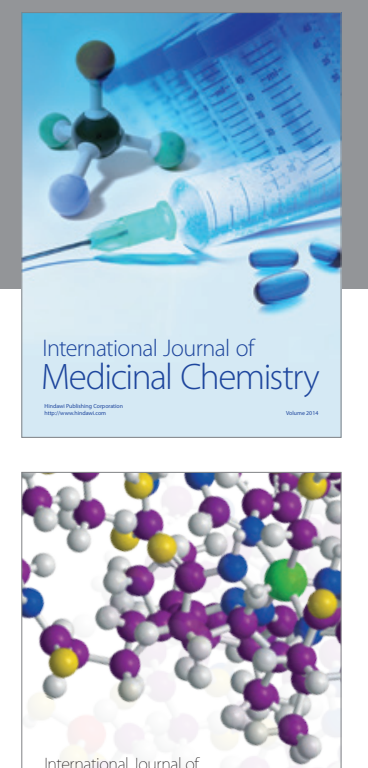

\section{Carbohydrate} Chemistry

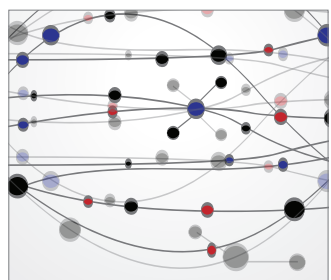

The Scientific World Journal
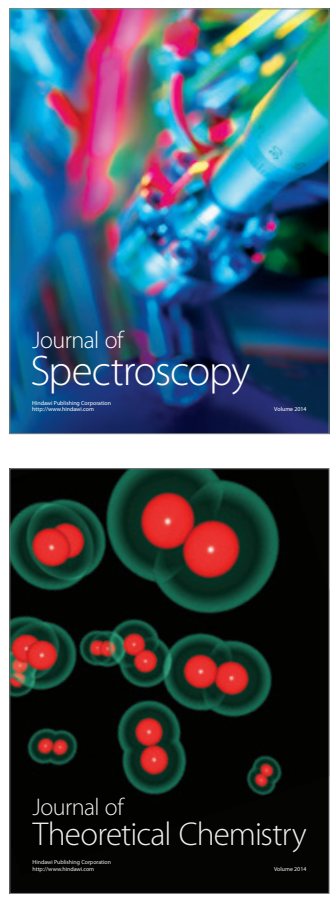
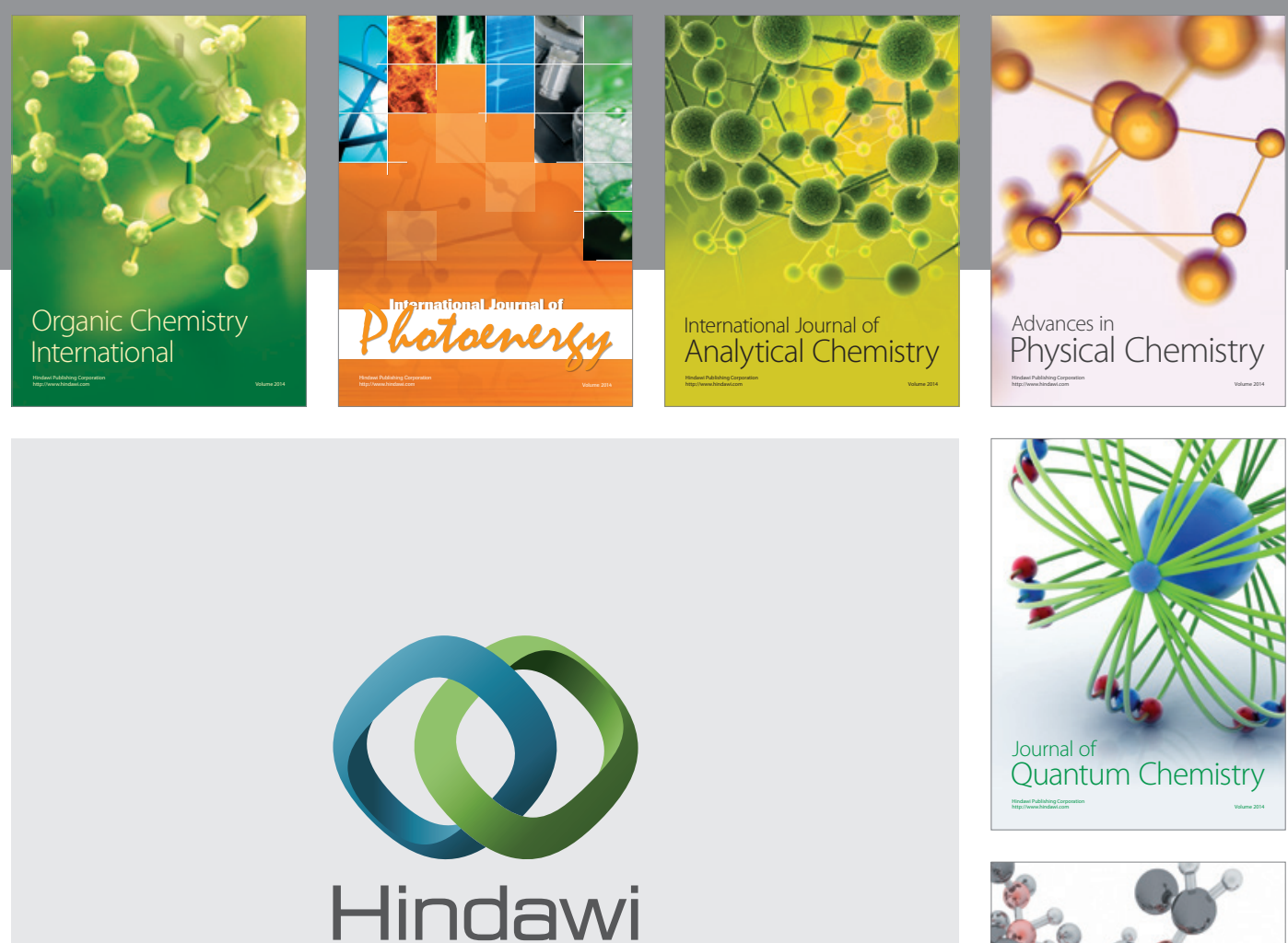

Submit your manuscripts at

http://www.hindawi.com

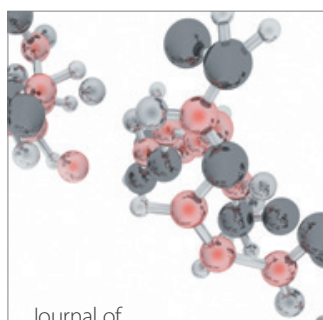

Analytical Methods

in Chemistry

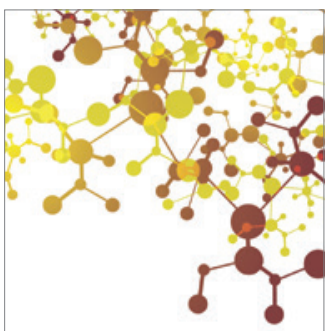

Journal of

Applied Chemistry

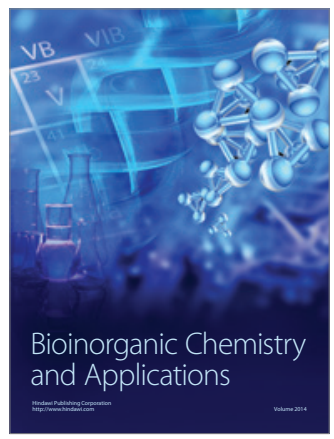

Inorganic Chemistry
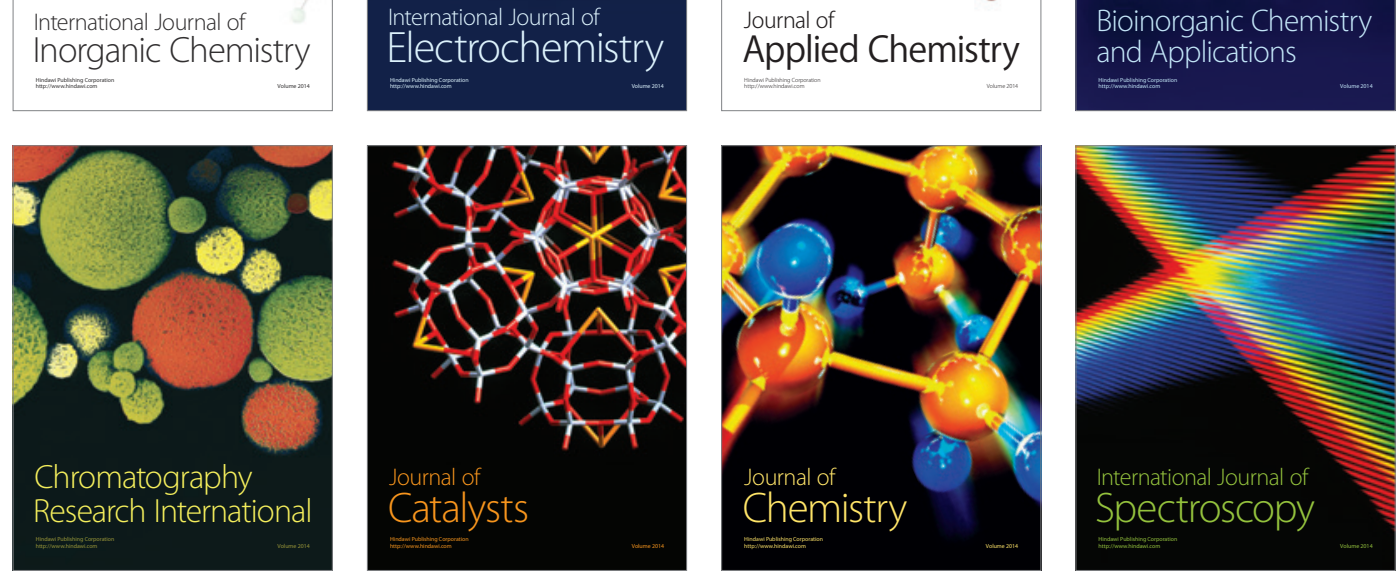